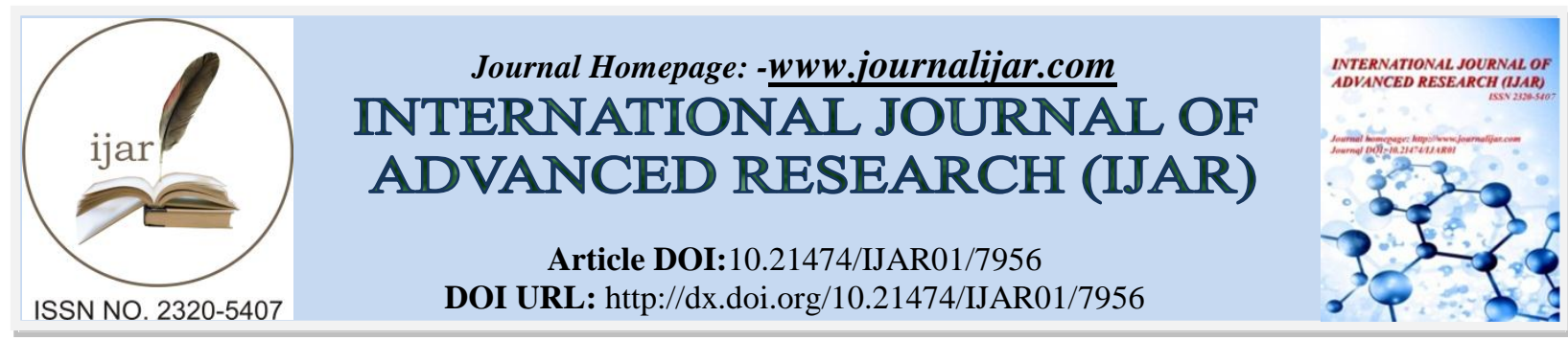

RESEARCH ARTICLE

\title{
NUMERICAL SIMULATION OF MIXED CONVECTIVE COOLING IN A HIGH RESIDENTIAL BUILDING DIVIDED INTO THREE STORIES.
}

Yawovi Nougbléga, Hodo- Abalo Samah, Kokou N'wuitcha, Kodjo Kpode and Magolmééna Banna. Laboratoire Sur l'Energie Solaire /Groupe Phénomène de Transfert et Energétique - Université de Lomé 01 BP 1515 Lomé 01-Togo.

\section{Manuscript Info}

Manuscript History

Received: 17 August 2018

Final Accepted: 19 September 2018

Published: October 2018

\section{Keywords:-}

Numerical simulation, mixed

convection, high divided ventilated

building, passive cooling, thermal comfort.

\section{Abstract}

Mixed convection heat transfer in a ventilated high building is numerically studied by solving mixed convection equations with the Boussinesq approximation.

The present investigation deals with velocity and temperature distribution in a high building divided into three stories; in which the left heated wall is vented by a fresh air stream introduced at various inlet openings and hot waste air exits from different outlet openings. Numerical solutions of the Navier Stokes equations and energy equation have been solved by the Thomas' algorithm. Solutions are presented for various geometrical aspect ratios and for different values of Grashof and Reynolds numbers. The results are presented in terms of streamlines, isotherms, velocity, and heat transfer versus the governing control parameters in detail.

Copy Right, IJAR, 2018,. All rights reserved.

\section{Introduction:-}

Conventional ventilation systems are based on mechanical components (pumps, compressors, blowers) that consume electric power. Heating in winter is also provided by means usually related to fuel consumption. Although these systems are effective, their construction and operation is expensive. Effective ventilation is important for various buildings, including houses, shelters, mobile homes, warehouses, greenhouses. Usually, ventilation is provided by systems based on mechanical components that consume electric power is not available. Also these systems are effective, their construction, operation and maintenance are expensive. In remote and desert areas where electric power is not available, conventional methods cannot be used. For reasons of energy savings and cost reduction, it becomes necessary to explore alternative ways for effective ventilation and heating. Hence passive ventilation based on natural convection has been extensively studied in laboratories in recent years. Both experimental investigations and numerical simulations have been performed and analyzed (Druckman S. et al., 2000; Glat Y.et al, 2000; Dubovsky V et al., 2001; Mazal B et al., 2001; Ziskind G. et al., 2001; Ziskind G. et al., 2002). From these studies, one can conclude that effective ventilation is achievable in small-scale laboratory models and real size one- story buildings. During the last decade, the idea of passive ventilation based on solar heating has gained growing interest. Special attention has been paid to the shape and size of the heated element that should transfer energy to the air, causing the latter to flow through the building. (Letan et al., 2003) numerically studied a multi-story building. They showed that both ventilation and heating can be achieved by natural convection. (Oosthuizen and Paul, 1985) numerically studied mixed convection heat transfer in a cavity with uniformly heated isothermal vertical walls and horizontal adiabatic walls. Forced flow was considered either aiding or opposing the buoyancy force effect. The cold wall was provided by two openings for the admission and evacuation of the forced stream. (Papanicolaou and 
Jaluria, 1990, 1993) numerically studied the mixed convection transport from an isolated heat source with a uniform heat flux input within a rectangular enclosure. Their results showed that the average Nusselt number increases by increasing the Richardson/(Reynolds) number with a fixed Reynolds/(Richardson) number. Also, heat transfer was found to increase by increasing the solid wall thermal conductivity. Later on, the same authors (Papanicolaou and Jaluria, 1994) studied mixed convection in a ventilated rectangular cavity containing heat sources. The results obtained show that the interaction between the sources is strongly dependent on their relative locations in the enclosure and their height. A sustained oscillatory behavior was obtained for $\mathrm{Gr} / \mathrm{Re}^{2}=50$. Mixed convection in a square enclosure with a partially partitioned was studied numerically by (Hsu et al., 1997). The results presented show that the average Nusselt number increases by increasing $\mathrm{Re} /\left(\mathrm{Gr} / \mathrm{Re}^{2}\right)$ for a given value of $\mathrm{Gr} / \mathrm{Re} \mathrm{e}^{2} /(\mathrm{Re})$. $\mathrm{Results}$ of the simulations indicate that heat dissipated from the source is maximum when the outflow opening is placed at the lower part of the vertical wall. Then laminar mixed convection in a two-dimensional enclosure with assisting and opposing flows was studied numerically by (Raji and Hasnaoui, 1998a) in the case of a cavity uniformly heated from one side wall or with prescribed equal heat fluxes on the top horizontal wall and the vertical left wall (Raji and Hasnaoui,2000). The obtained results show that the Re-Ra plane can be divided into regions corresponding to the dominance of the forced convection or to the mixed convection regime where the maximum heat transfer (maximum thermal interaction between forced and natural convection) and the limits between both regimes were correlated in terms of Re versus Ra. (Manca et al. 2003) studied numerically the effect of the heated wall position on mixed convection in a partially open cavity. The results showed that the maximum temperature values decrease by increasing the Reynolds and the Richardson numbers. Also, the opposing forced flow configuration was found to achieve the highest thermal performance in terms of both maximum temperature and average Nusselt number. Laminar mixed convection in a two dimensional enclosure, differentially heated, was studied numerically by (Singh and Sharif 2003). They reported that maximum cooling effectiveness is achieved if the inlet and the outlet openings are, respectively, located near the bottom of the cold wall and the top of the hot wall. Laminar double diffusion mixed convection in a two-dimensional ventilated enclosure was numerically investigated by (Deng et al., 2004). The combined effects of the Grashof number, the Reynolds number, the buoyancy ratio and the ventilation mode on the indoor air environment were examined. Then, natural convection in enclosures has been a topic of great interest. (I. Catton et al., 1979) and (S. Ostrach et al., 1972) reviewed the literature pertaining to natural convection in enclosures. The study of the transient removal of a contaminant from a two-dimensional enclosure has been carried out by (J.L.Lage et al., 1991,1992.) .It has been shown that significant gains in ventilation efficiency can be made by properly orienting and positioning the inlet and outlet ports relative to each other and to the enclosure.

On the basis of the literature review, it appears that no work was reported on mixed convection in a high buildings divided into three stories. Therefore, due to its practical interest for energy saving, the subject needs to be further explored to improve knowledge in this field. Hence, the aim of the present study consists in numerically studying a mixed convection problem in a high ventilated building divided into three floors submitted to a constant heat flux along its left vertical wall. In this analysis, the forced flow enters the high building divided into three stories through the openings respectively located in the middle of the heated vertical left wall of each floor and leaves it from the openings located in the right opposite adiabatic wall. This kind of ventilation supports a double interaction between buoyancy-induced flow and forced flow. In the lower part of the high building, the forced flow injected in the high building divided into three stories promotes the natural convection motion. Thus, the combined effects of the Rayleigh number and the intensity of the imposed flow (through the Reynolds number) on the flow structure and heat transfer across the high building is examined for this specific situation.

\section{Mathematical Formulation:- Physical Model and Governing Equations:-}

The configuration under study with the system of coordinates is sketched in Fig. 1. It consists of a high ventilated building divided into three stories heated by a uniform heat flux from its vertical left wall while the remaining walls are considered perfectly insulated. The system is submitted to an imposed flow of fresh air, parallel to the horizontal walls, entering the building from three inlet openings located respectively at the middle of the left vertical wall of the stories and leaving through the outlet openings. The third dimension of the high building (direction perpendicular to the plane of the diagram) is assumed to be large enough so that fluid motion can be considered twodimensional. Flow is assumed to be laminar and incompressible with negligible viscous dissipation. 
Adiabatic wall

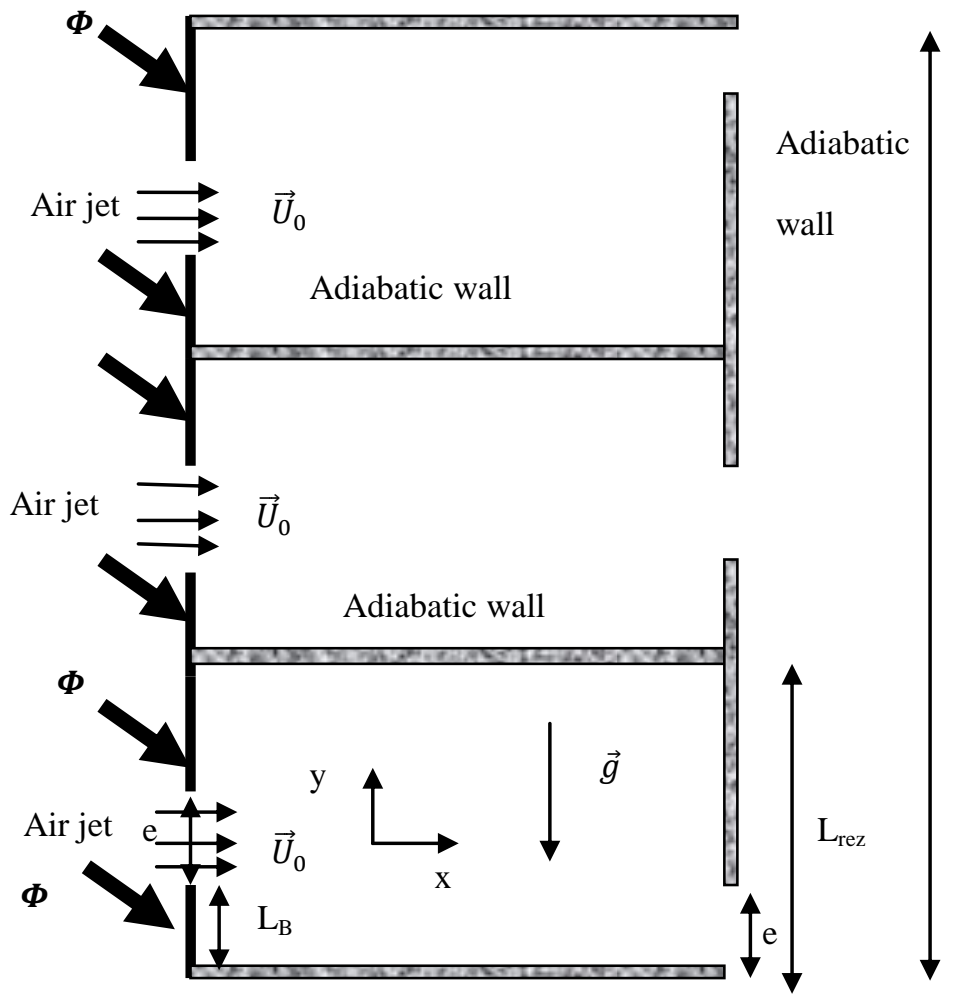

$\mathrm{L}$

Adiabatic floor

$\mathrm{H}$

Fig.1:- Physical model

All the thermophysical properties of the coolant fluid are assumed constant except density that gives rise to the buoyancy forces (Boussinesq approximation). Taking into account the above-mentioned assumptions, the nondimensional governing equations, written in vorticity - streamlines $(\boldsymbol{\omega}-\psi)$ formulation, are as follows:

\section{Mathematical Formulation:-}

$\frac{\partial U}{\partial X}+\frac{\partial V}{\partial Y}=0$

$\frac{\partial \omega}{\partial \tau}+U \frac{\partial \omega}{\partial X}+V \frac{\partial \omega}{\partial Y}=R i \frac{\partial \theta}{\partial X}+\frac{1}{R e}\left(\frac{\partial^{2} \omega}{\partial X^{2}}+\frac{\partial^{2} \omega}{\partial Y^{2}}\right)$

$\frac{\partial \theta}{\partial \tau}+U \frac{\partial \theta}{\partial X}+V \frac{\partial \theta}{\partial Y}=\frac{1}{R e P r}\left(\frac{\partial^{2} \theta}{\partial X^{2}}+\frac{\partial^{2} \theta}{\partial Y^{2}}\right)$

$\omega=-\left(\frac{\partial^{2} \Psi}{\partial X^{2}}+\frac{\partial^{2} \Psi}{\partial Y^{2}}\right)$

\section{Boundary Conditions:-}

- Initial conditions: at $\tau=0$ :

$\theta=\omega=U=V=\psi=0$

- at $\tau>0$

The boundary conditions associated with the problem are found below.

At the left, right, top and bottom walls:

$X=0$ and $0<Y<\frac{L_{B}}{L_{\text {rez }}} ; U=V=\psi=0 ; \omega=-\left.\frac{\partial^{2} \psi}{\partial x^{2}}\right|_{X=0} ;\left.\frac{\partial \theta}{\partial X}\right|_{X=0}=-1$

$X=0$ and $\frac{L_{B}}{L_{r e z}}<Y<\frac{\left(e+L_{B}\right)}{L_{r e z}} ; U=1 ; \psi=Y-E ; V=\omega=\theta=0$ 


$$
\begin{aligned}
& X=0 \text { and } \frac{\left(L_{B}+e\right)}{L_{r e z}}<Y<\frac{L_{r e z}}{L_{r e z}} ; U=V=\psi=0 ; \omega=-\left.\frac{\partial^{2} \psi}{\partial x^{2}}\right|_{X=0} ;\left.\frac{\partial \theta}{\partial X}\right|_{X=0}=-1 \\
& Y=0 \text { and } 0<X<\frac{H}{L_{r e z}} ; U=V=\psi=0 ; \omega=-\left.\frac{\partial^{2} \psi}{\partial Y^{2}}\right|_{Y=0} ;\left.\frac{\partial \theta}{\partial Y}\right|_{Y=0}=0 \\
& X=\frac{H}{L_{r e z}} \text { and } 0<Y<\frac{e}{L_{r e z}} ;\left.\frac{\partial U}{\partial X}\right|_{X=S}=\left.\frac{\partial V}{\partial X}\right|_{X=S}=\left.\frac{\partial \psi}{\partial X}\right|_{X=S}=\left.\frac{\partial \omega}{\partial X}\right|_{X=S}=\left.\frac{\partial \theta}{\partial X}\right|_{X=S}=0 \\
& X=\frac{H}{L_{r e z}} \text { and } \frac{e}{L_{r e z}}<Y<\frac{L_{r e z}}{L_{r e z}} ; U=V=\psi=0 ; \omega=-\left.\frac{\partial^{2} \psi}{\partial X^{2}}\right|_{X=S} ;\left.\frac{\partial \theta}{\partial X}\right|_{X=S}=0 \\
& Y=\frac{L_{r e z}}{L_{r e z}} \text { and } 0<X<\frac{H}{L_{r e z}} ; U=V=\psi=0 ; \omega=-\left.\frac{\partial^{2} \psi}{\partial Y^{2}}\right|_{Y=\frac{L_{r e} e}{L_{r e z}}} ;\left.\frac{\partial \theta}{\partial Y}\right|_{Y=\frac{L_{r e}}{L_{r e z}}}=0
\end{aligned}
$$

The same boundary conditions are written for the second and the third floors of the high building. No slip and impermeability boundary conditions have been used on all walls except at inlet and outlet openings.

Stream function and vorticity are related to the velocity components by the following expressions:

$U=\frac{\partial \psi}{\partial Y}, \quad V=-\frac{\partial \psi}{\partial X}$ and $\omega=\left(\frac{\partial V}{\partial X}-\frac{\partial U}{\partial Y}\right)$

Where the scales are defined: $(X, Y)=\left(\frac{x}{L_{r e z}}, \frac{y}{L_{r e z}}\right) ; \tau=\frac{u_{0 t}}{L_{r e z}} ;(U, V)=\left(\frac{u}{u_{0}}, \frac{v}{u_{0}}\right)$

$\Psi=\frac{\psi}{u_{0} L_{r e z}} ; \omega=\frac{\Omega L_{r e z}}{u_{0}} ; \theta=\frac{\lambda\left(T-T_{a}\right)}{\emptyset L_{r e z}} ; R e=\frac{\rho u_{0}(2 e)}{\mu} ; G r=\frac{\rho^{2} g \beta \emptyset\left(L_{r e z}\right)^{4}}{\lambda \mu^{2}}$

and the aspect ratio expressed as: $A=L / H ; E=e / L_{\text {rez }} ; S=H / L_{\text {rez }}$

\section{Evaluation Of The Model Characteristics:-}

From the engineering viewpoint, the most important concern is heat transfer through the heated walls. These are best represented by the Nusselt number, which is a measure of the ratio of the heat transfer by conduction to the flux convected by fluid flow. The local Nusselt numbers on the heated walls are given by:

$N u_{w}=\frac{\emptyset L_{r e z}}{\lambda\left(T_{W}-T_{a}\right)}=1 / \theta_{w}$

\section{Numerical Procedure:- \\ Method Of Solution:-}

The nonlinear partial differential governing equations (1-3), were discretized using a finite difference technique. The first and second derivatives of the diffusive terms were approached by central differences while a second order upwind scheme was used for the convective terms to avoid possible instabilities frequently encountered in mixed convection problems. The integration of the algebraic equations (2) and (3) was assured by the Thomas' algorithm. At each time step, the Poisson equation, Eq. (4), was treated using the Point Successive Under-Relaxation method (PSUR) with an optimum under-relaxation coefficient equal to 0.8 for the grid $(121 \times 61)$ adopted in the present study. Convergence of iteration for stream function solution is obtained at each time step .The following criterion is employed to check for steady-state solution. Convergence of solutions is assumed when the relative error for each variable between consecutive iterations is below the convergence criterion $\varepsilon$ such that $\sum\left|\left(\varnothing_{i, j}^{n+1}-\emptyset_{i, j}^{n}\right) / \emptyset_{i, j}^{n+1}\right|<$ $10^{-5}$ where $\phi$ stands for $\psi, \theta, \omega, \mathrm{n}$ refers to time and $i$ and $j$ refer to space coordinates. The time step used in the computations is $\Delta \tau=10^{-5}$. Grid independency solutions are assured by comparing different grid meshes for the highest Grashof and Reynolds numbers used in this work $\left(\mathrm{Gr}=10^{6}\right.$ and $\left.\mathrm{Re}=200\right)$. It was found that the differences between meshes of 121 x 121 and 141x141 were not significant for all variables. The results obtained with these grids were comparable to those obtained with a non-uniform grid size of $121 \mathrm{x} 61$. Thus, a non-uniform mesh of 121 x61 was selected. The vorticity computational formula of (Woods .L. C, 1954) for approximating the wall vorticity was used: $\omega_{P}=\frac{1}{2} \omega_{P+1}-\frac{3}{\Delta \eta^{2}}\left(\psi_{P+1}-\psi_{P}\right)$, where $\psi_{P}$ and $\psi_{P+1}$ are stream function values at the points adjacent to the boundary wall; $\mathrm{n}$ the normal abscise on the boundary wall. 
Table 1:- Grid independency

\begin{tabular}{|l|l|l|l|l|l|l|}
\hline stage & $\boldsymbol{\Psi}_{\max }$ & Change (\%) & $\boldsymbol{\Theta}_{\max }$ & Change (\%) & Nus $_{\operatorname{moy}}$ & Change (\%) \\
\hline $\mathbf{1 2 1 x 1 2 1}$ & 0.22499 & - & 0.30153 & - & 10,50050 & - \\
\hline $\mathbf{1 4 1 x 1 4 1}$ & 0.23350 & 3.64453 & 0.27829 & 7.70735 & 10,87278 & 3.42396 \\
\hline $\mathbf{1 2 1 x 6 1}$ & 0.24999 & 6.59626 & 0.29756 & 6.47600 & 10,81007 & 0.58010 \\
\hline
\end{tabular}

\section{Validation:-}

In order to test the computer code developed for this study, the problem of a ventilated rectangular enclosure with its left and upper walls submitted to a constant heat flux, while the remaining walls are considered adiabatic was studied. Very good agreement is obtained between the test problem solution and the ventilated rectangular enclosure solutions according to the work of (A. Raji et al., 2000). The horizontal cold jet enters the enclosure from the bottom of its heated wall and leaves from the top of the other vertical wall with no slip boundary conditions applied to all the walls. The Reynolds number, Re was set at 100 , for Raleigh number Ra set at $10^{6}$.The numerical analysis predicted values of streamlines and isotherms together with ventilated rectangular enclosure results shown in fig.2.

$$
\operatorname{Re}=100, \operatorname{Ra}=10^{6}
$$

\section{A. Raji}
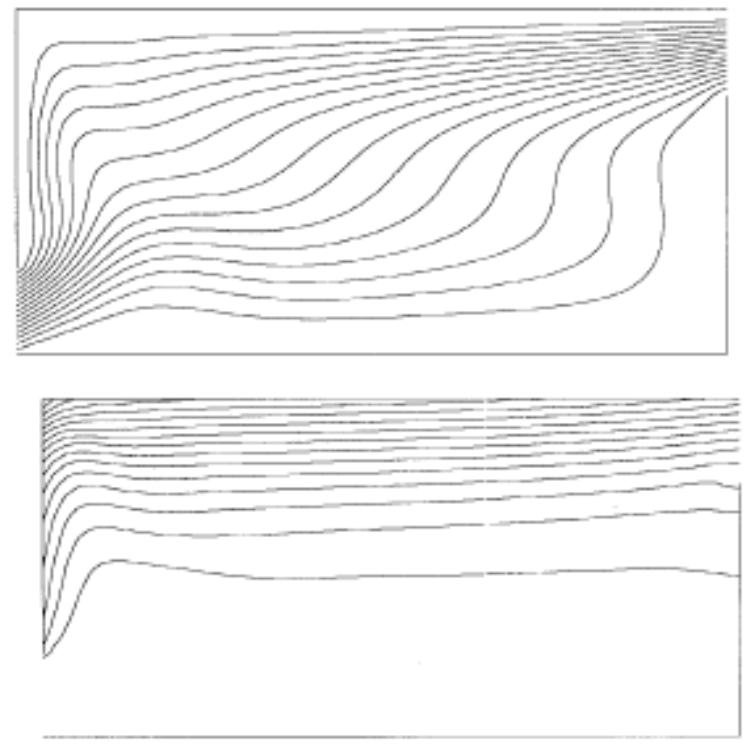

\section{Present work}

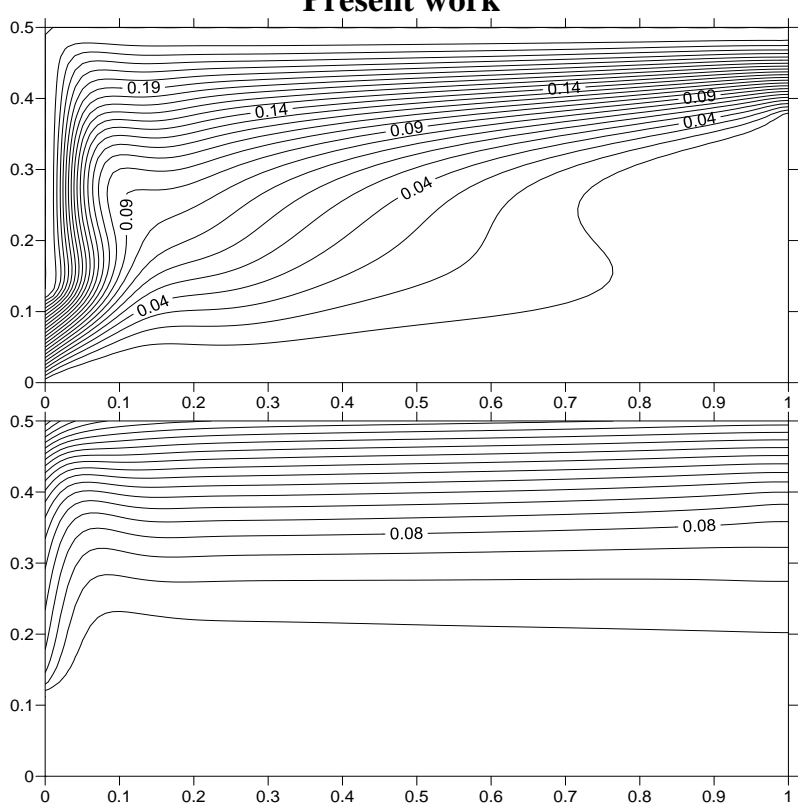

Fig.2:- Comparison of streamlines and isotherms

\section{Results And Discussion:- \\ Flow Characteristic:-}

In the following, the effects of the Grashof number $\left(0 \leq \mathrm{Gr} \leq 10^{6}\right)$ and the Reynolds number $(10 \leq \operatorname{Re} \leq 200)$ on fluid flow and temperature distribution are illustrated.

The calculations were conducted by considering air as a working fluid $(\operatorname{Pr}=0.72)$. The geometrical aspect ratio, $\mathrm{A}=$ $\mathrm{L} / \mathrm{H}$, and the relative height of the openings for each story, $\mathrm{E}=\mathrm{e} / \mathrm{L}$, are maintained constant at 2 and $1 / 4$, respectively.

The effect of the Reynolds number on the flow structure and temperature distribution is shown in Fig.2 (a-c). The streamlines and the isotherms are presented for steady state flows obtained for $\mathrm{Gr}=10^{6}$ and values of the Reynolds number ranging between 30 and 100. For $\operatorname{Re}=30$, the analysis of the streamlines in Fig. 2a reveals a complex 
structure in the whole building. It reveals that there is a mixed convection on the first story of the building, while the manifestation of the natural convective flow is respectively observed on the second and third floors. By increasing the Reynolds number, the closed cells and the open lines appear simultaneously on the three stories. This situation indicates the real manifestation of the mixed convection in the high building, Fig.2 (b-c).

In fact, the heated portions of the left wall, located above the inlet openings, impose a clockwise circulation on the stories. The lower closed cells will play an increasingly important role by increasing Re since the more intense is the forced flow, the greater its negative (positive) effect on the natural convection flow in the upper (lower) part of the divided high building.

a

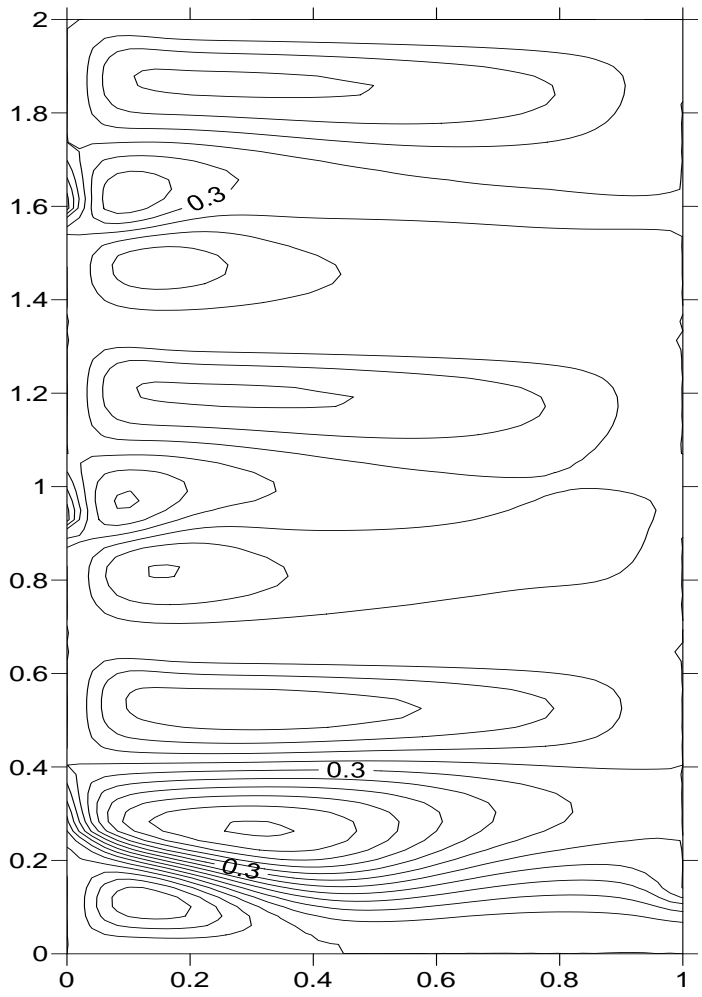

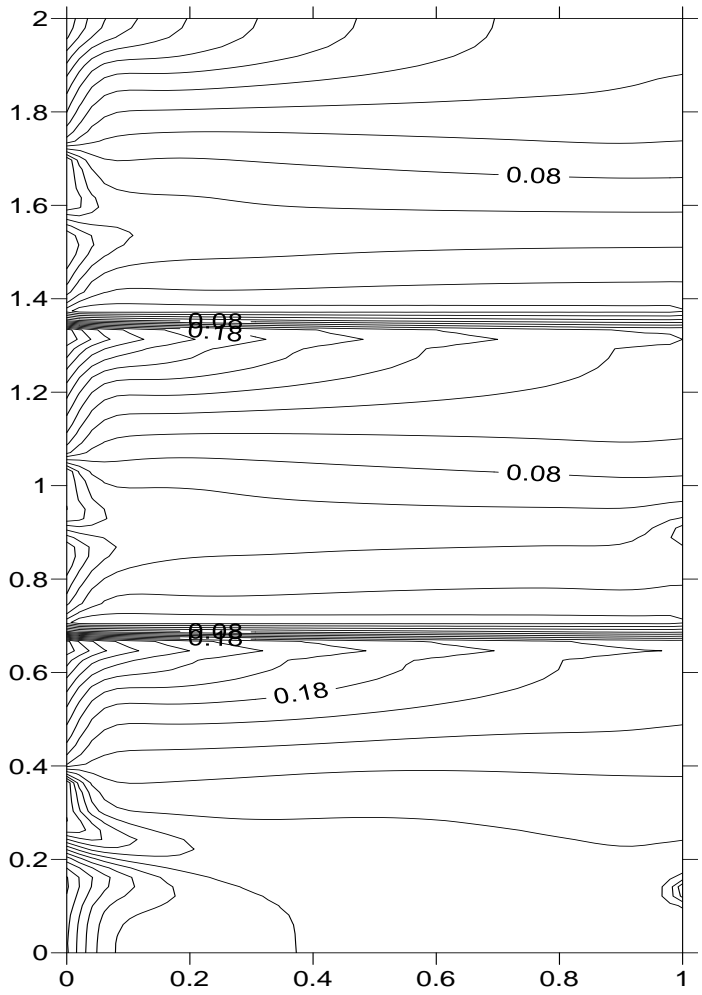


b

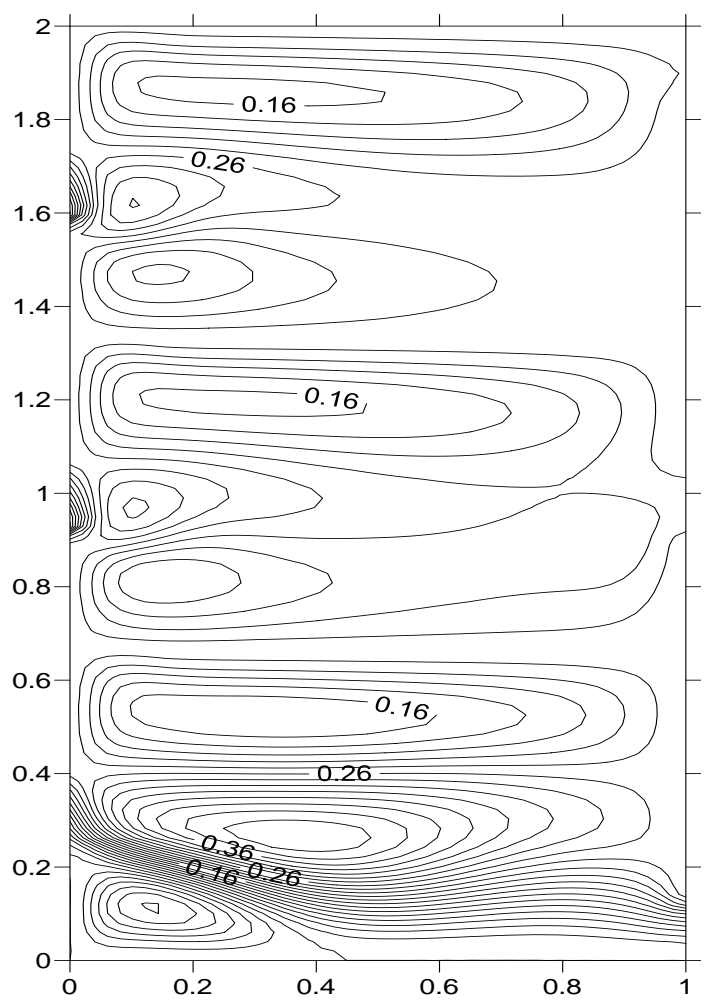

$\mathrm{c}$

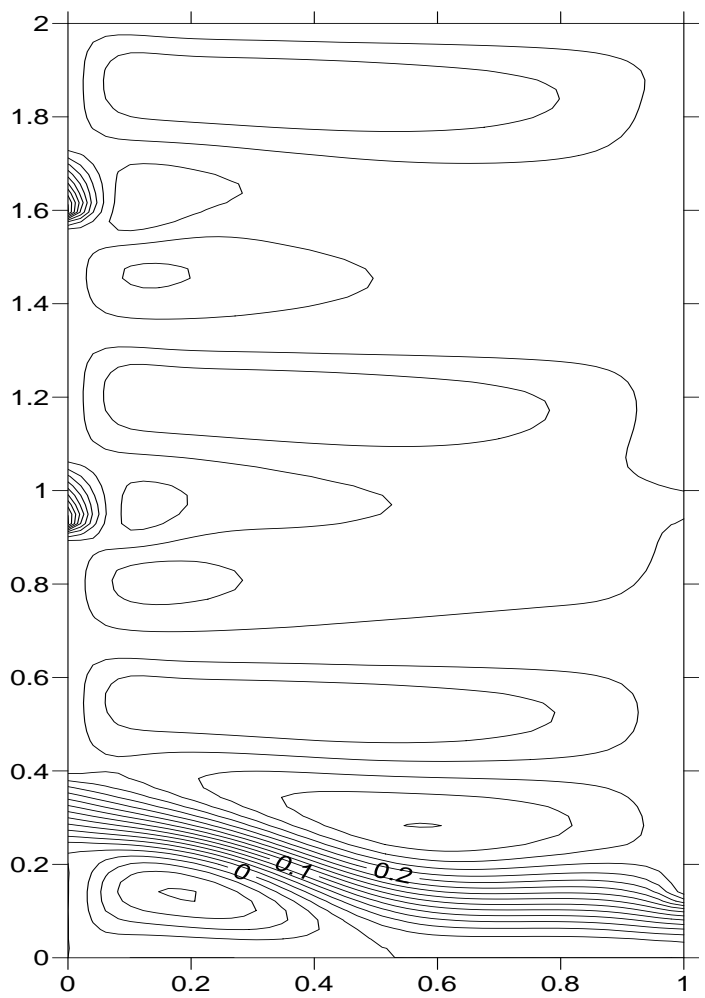

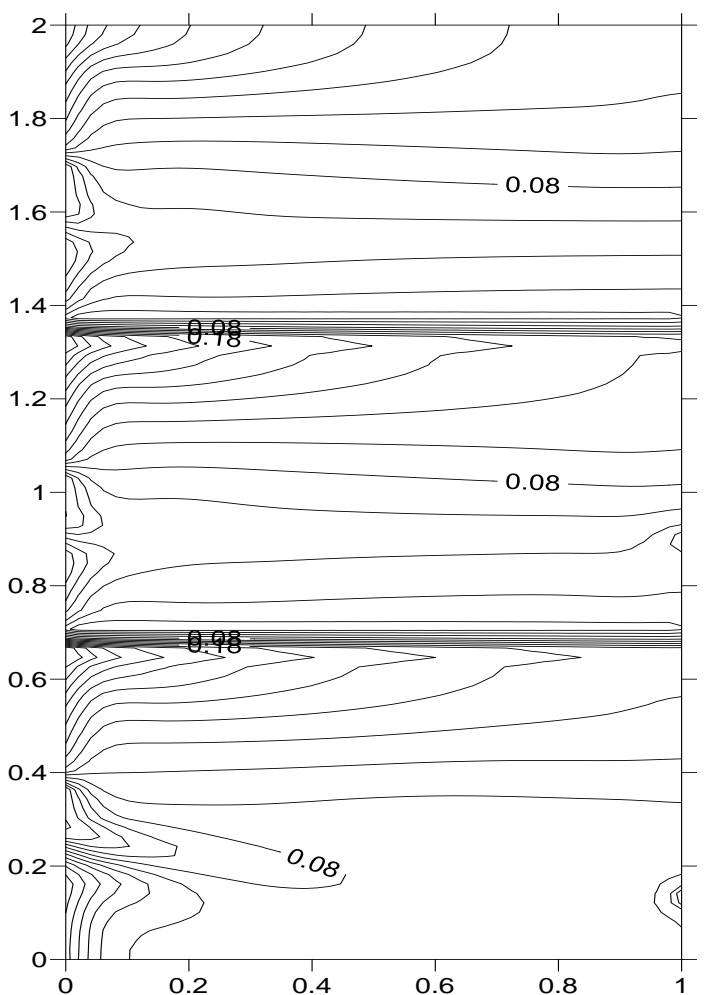

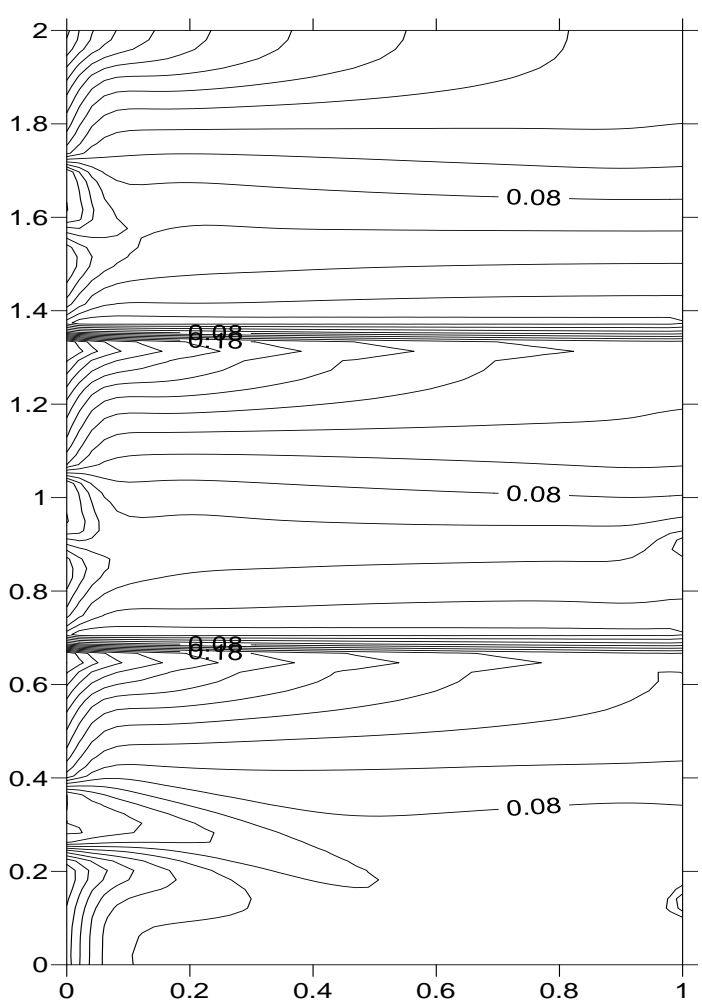

Fig.3:- Streamlines and isotherms obtained for $\mathrm{Gr}=10^{6}$ and different values of $\operatorname{Re}$ : (a) $\operatorname{Re}=30$; (b) $\operatorname{Re}=50$; (c) $\operatorname{Re}=100$

The corresponding isotherms are more tightened in the vicinity of the heated wall testifying to a noticeable increase in convective heat exchange. In addition, a net progression of the cold zone towards the right wall is observed on the 
floors. A further increase of Reynolds number acts by increasing the aiding role of forced and natural convection on the floors of the high building.

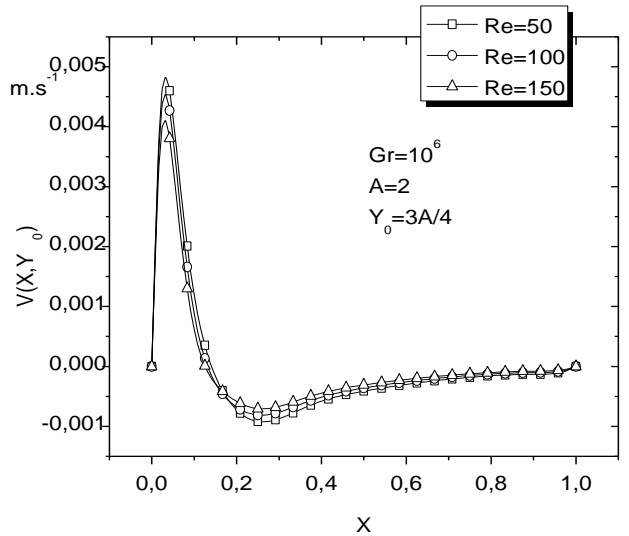

(a) Vertical velocity component

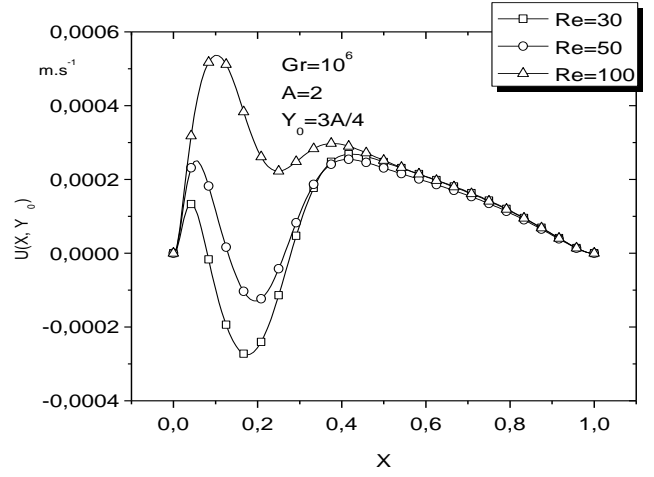

(b) Horizontal velocity component

Fig.4:- Variation of the velocity components versus Reynolds number

Fig.4(a-b) showed the variation of the velocity components in the building, hence the vertical velocity component as the horizontal velocity component increases and reaches the maximal value before decreasing to the minimal value and increases again to attain the maximal value and decreasing along the right wall. This variation of the velocity components indicated that the no slip and impermeability condition is respected along the walls of the building. The maximum values near the heated walls indicated that cooling is more important in these zones, and the negative values showed that there are recirculation zones in the building.

Fig.5(b) shows that air temperature in the building is stratified along the height of the stories, while fig.5(a) indicated that for a fixed Reynolds number, the temperature of the coolant fluid is a decreasing function along the length $(\mathrm{H})$ of the building.

For different values of the Reynolds number or for the inlet jet of the fresh air in the building, the difference between the ambient temperature and the internal temperature is less equal to $5 \mathrm{~K}$. This behavior situation indicates that thermal comfort is attained in the building, fig.5 (a-b). In fig.6, the local Nusselt number is an increasing function along the length of the building for a fixed Reynolds number. One can show that the second floor is less heated than the first floor in the high building. Because the Nusselt number is defined as the inverse value of the dimensionless temperature along the heated walls in the building.
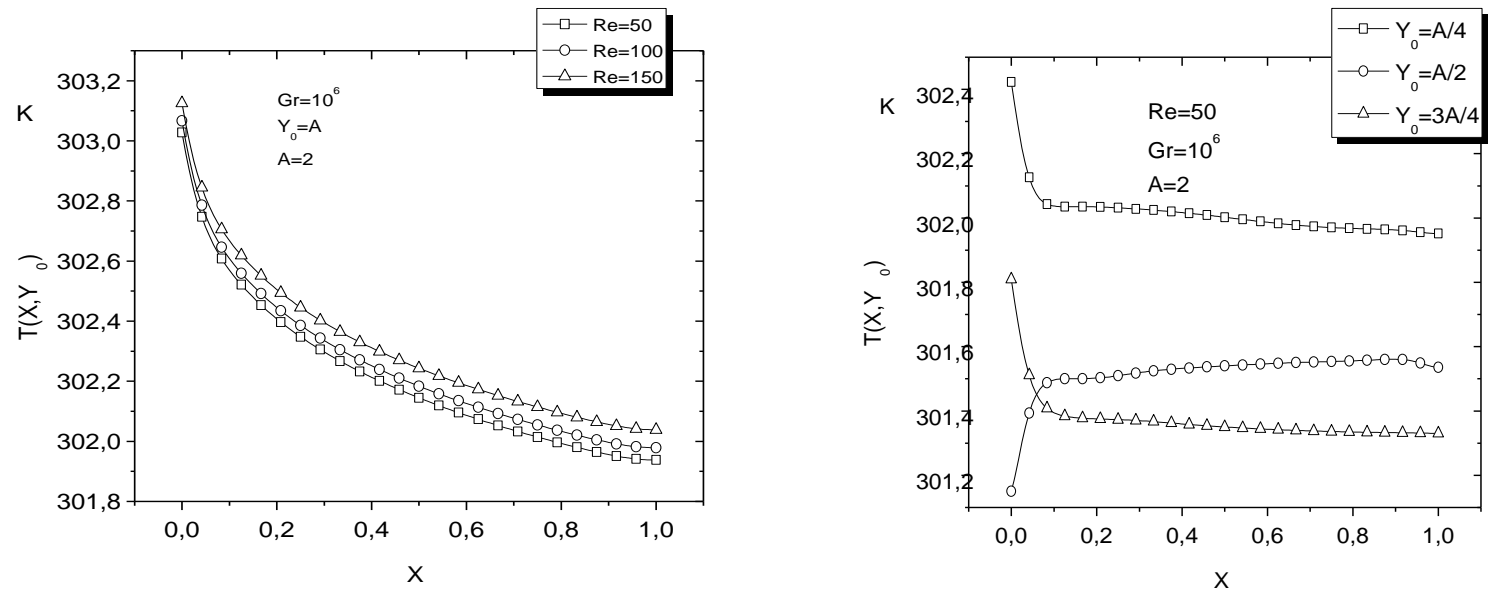
(a) Top node

Fig.5:- Variation of the temperature along the building

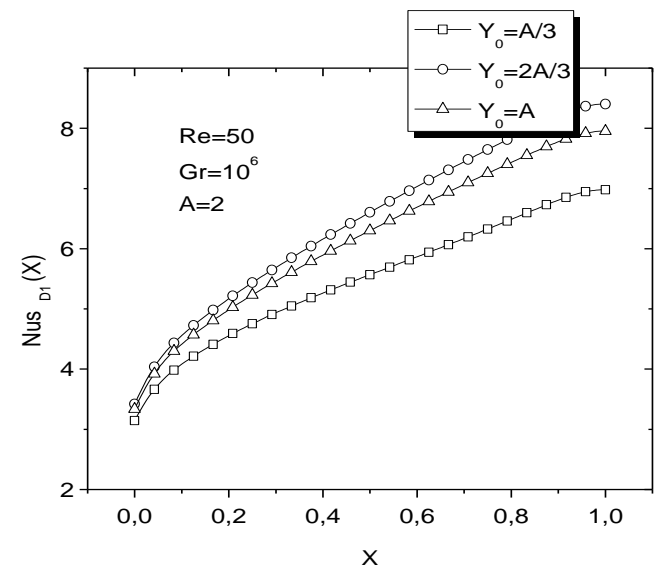

Fig.6:- Variation of local Nusselt number along the floors of the building

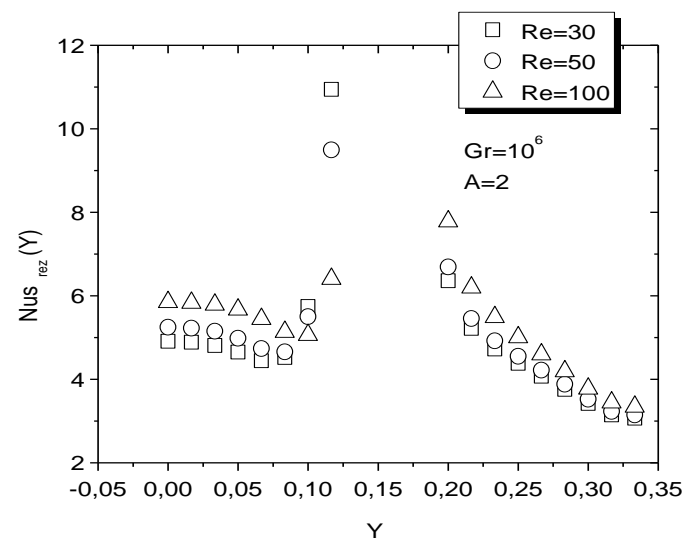

(a) First story left heated wall

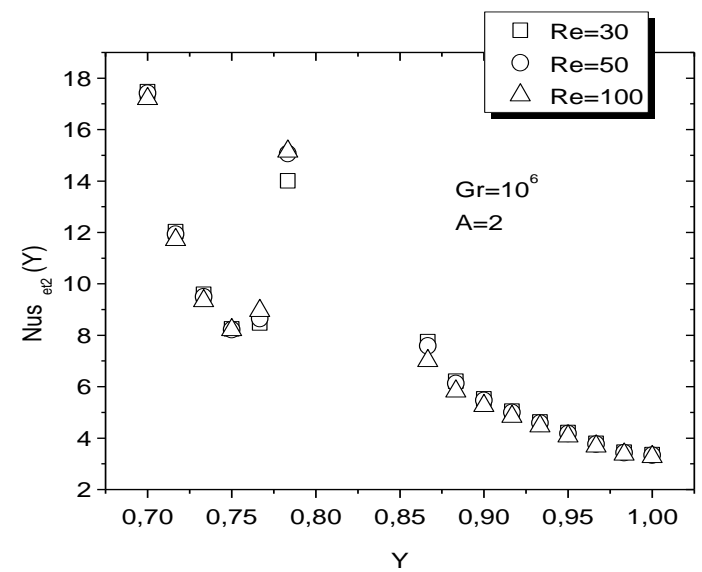

(c) Third story left heated wall

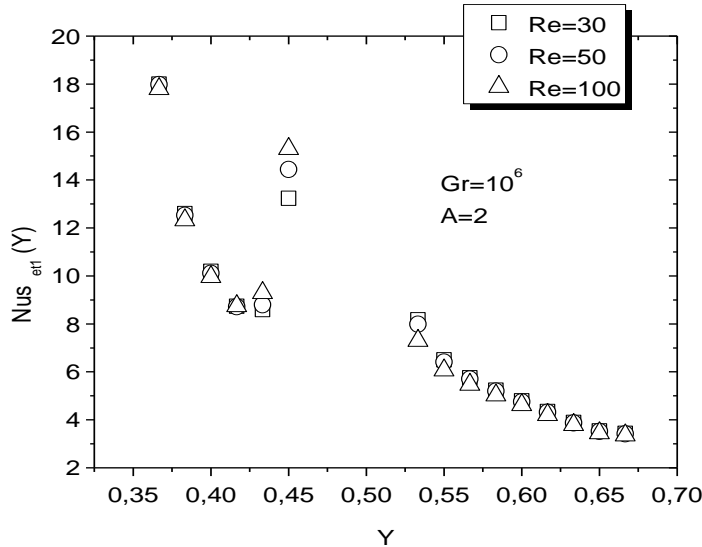

(b) Second story left heated wall 
Fig.7:- Variation of local Nusselt number along the left heated wall of the building

As shown in fig.7 (a-c), the local Nusselt number decreases to the minimal value along the first part of the left heated wall on the stories and then increases to the maximal value near the inlet opening. Then, the local Nusselt number is a decreasing function along the second heated part of the left wall, for the fixed Reynolds number. This variation of the local Nusselt number indicates that the heat exchange is respectively more important before the inlet opening on the stories in the divided high building.

a

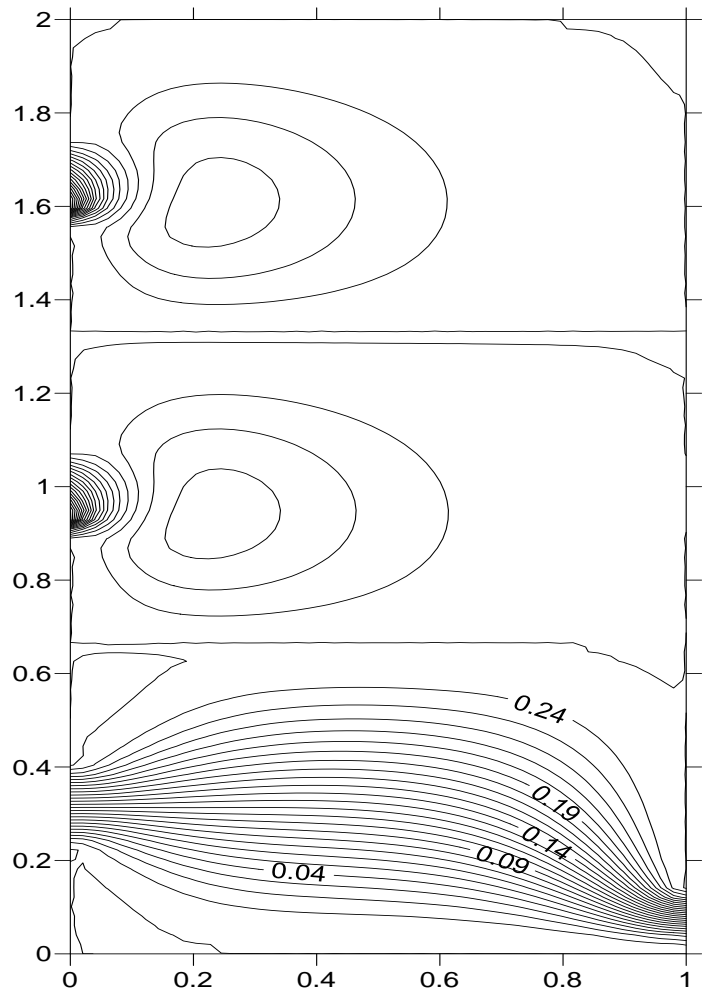

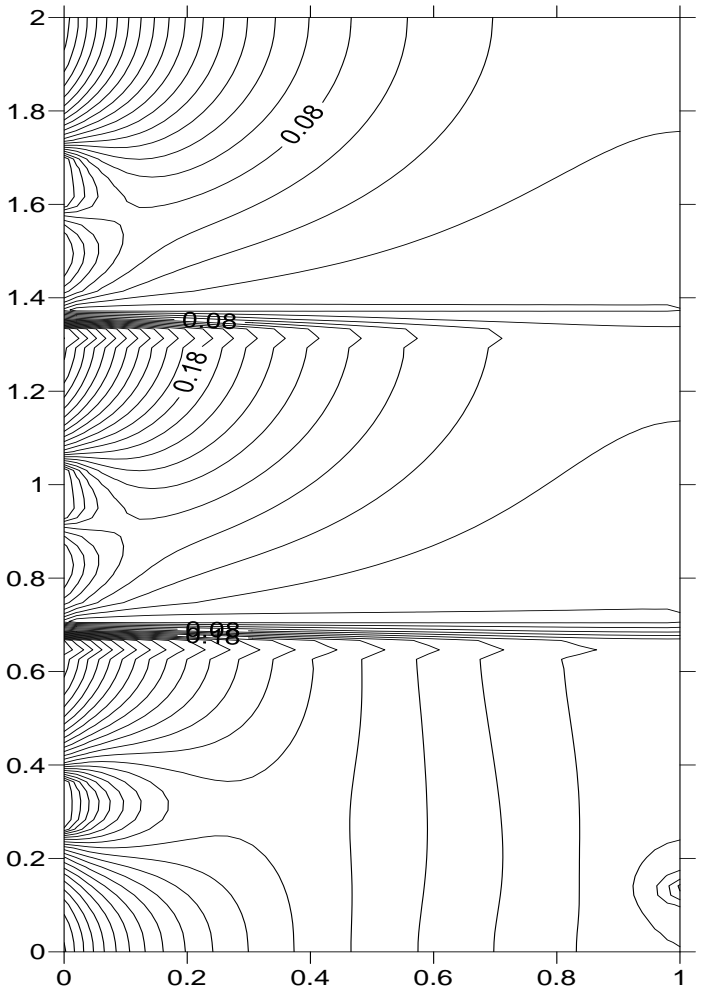


b

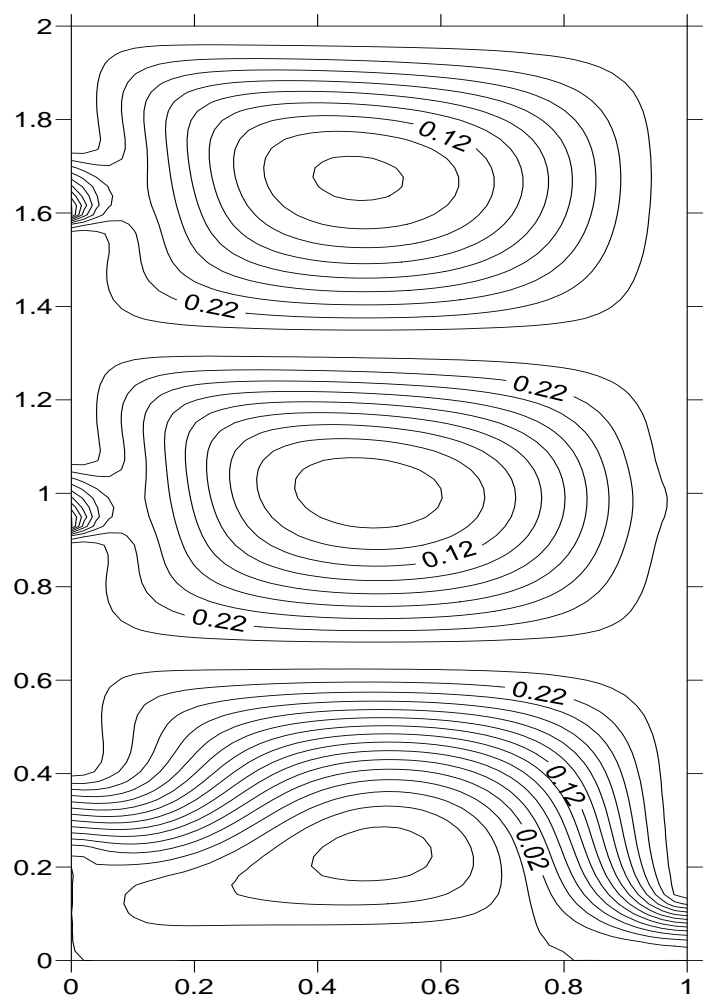

c

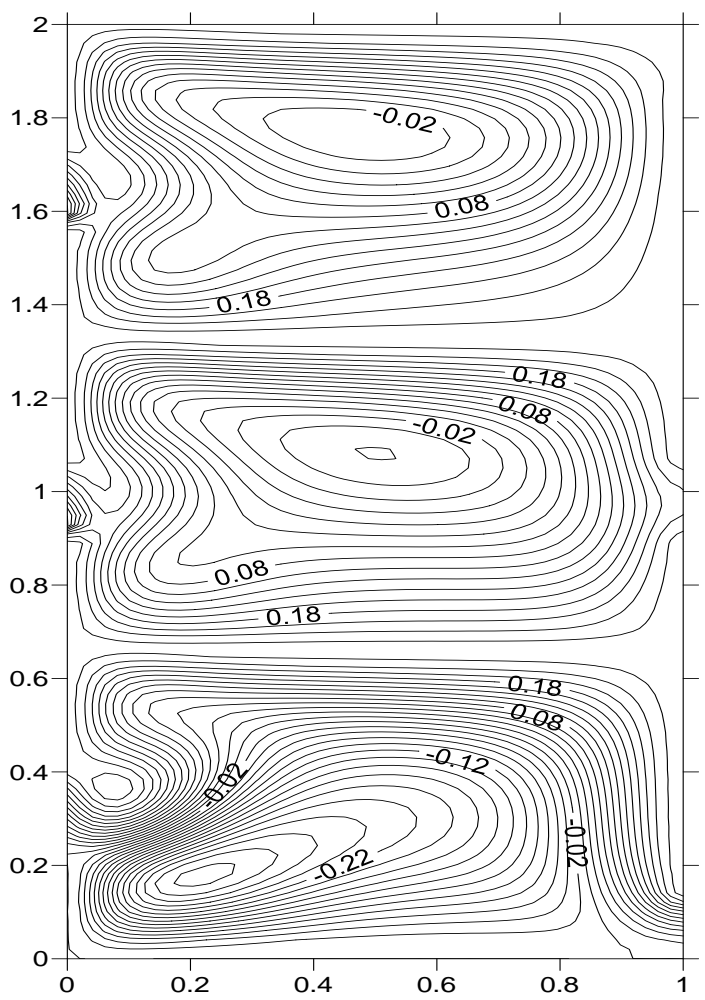

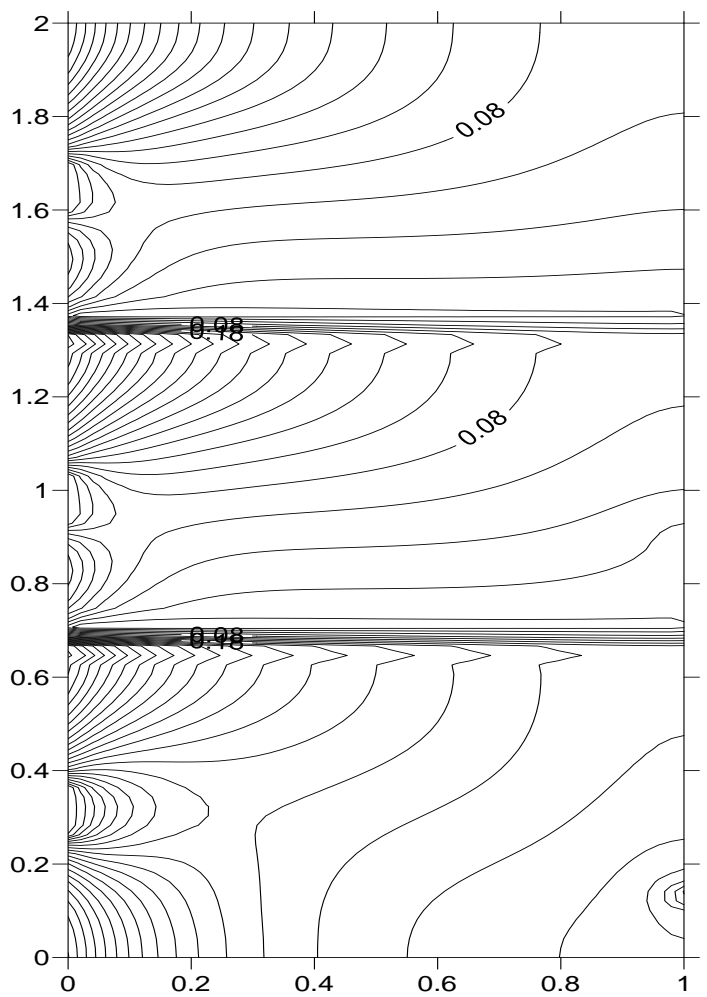

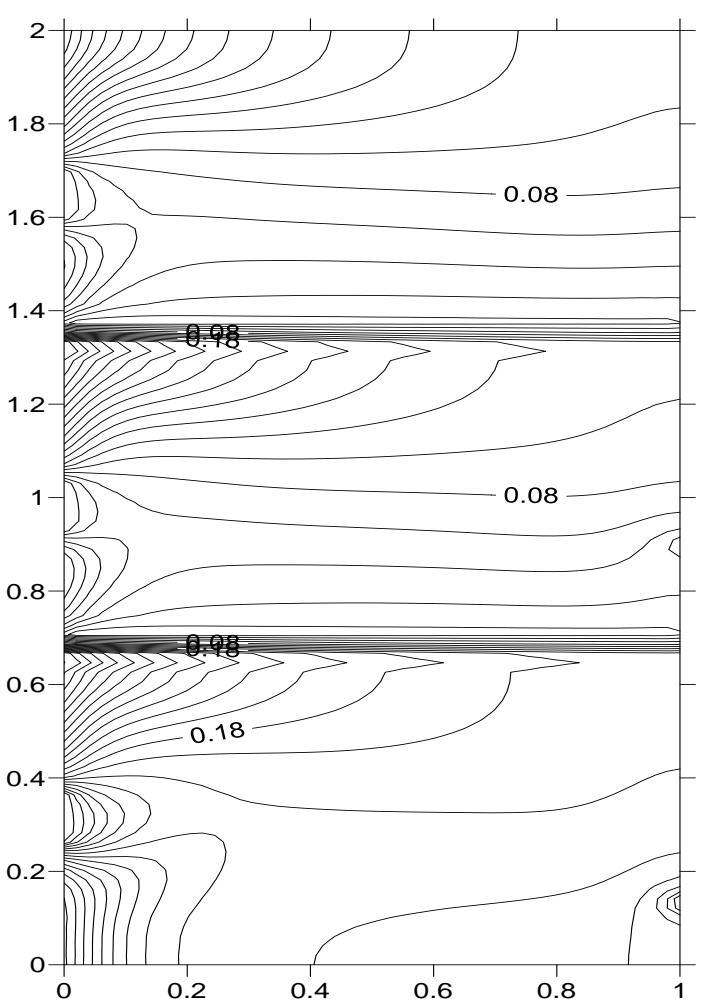


d
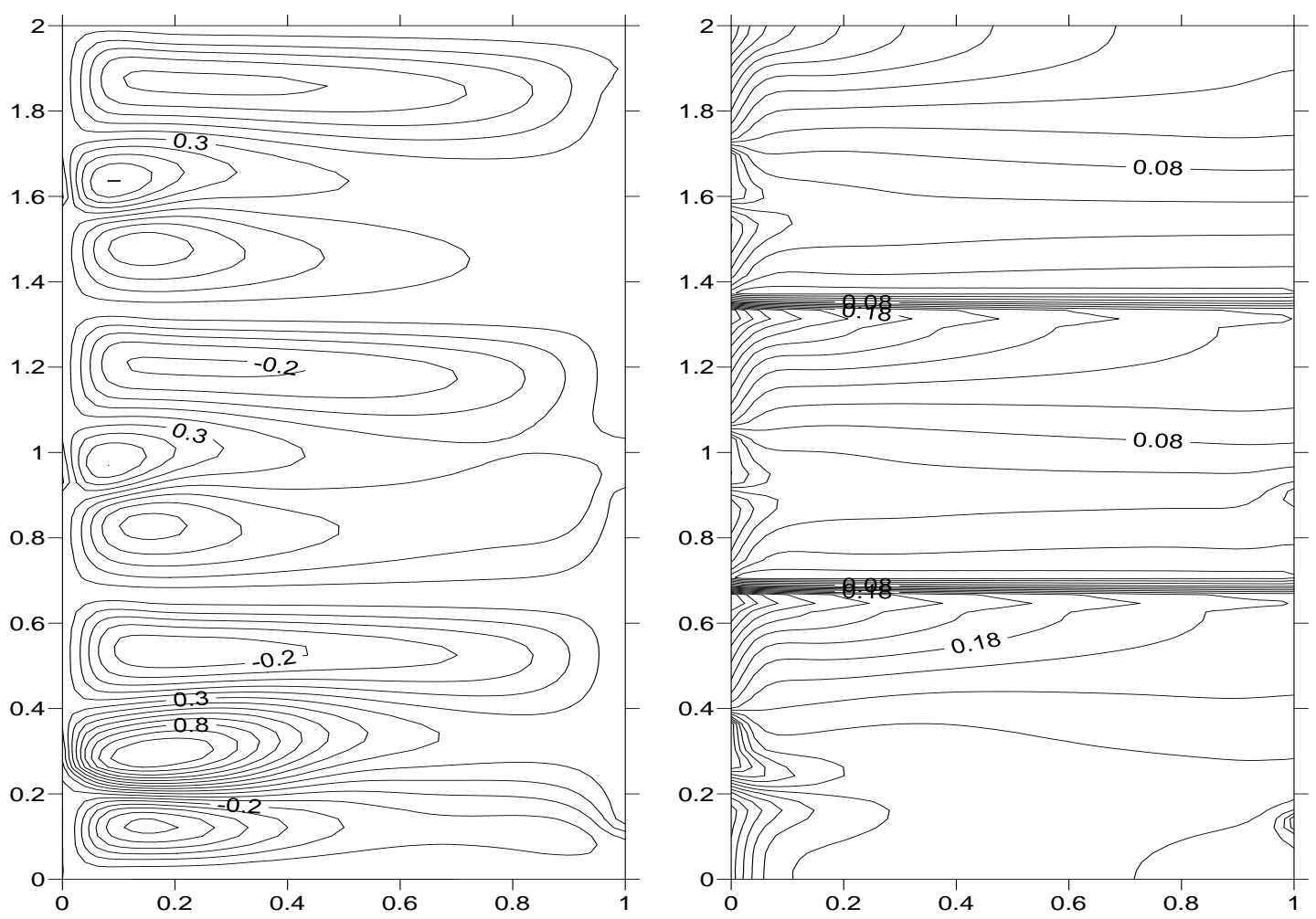

Fig.8:- Streamlines and isotherms obtained for $\mathrm{Re}=10$ and different values of Grashof number: (a) $\mathrm{Gr}=0$; (b) $\mathrm{Gr}$ $=10^{4}$, (c) $\mathrm{Gr}=10^{5}$, (d) $\mathrm{Gr}=10^{6}$

In the following, the effect of Grashof number $\left(0 \leq \mathrm{Gr} \leq 10^{6}\right)$ for a fixed Reynolds number $(\operatorname{Re}=10)$ is presented. The basic forced convection flow, presented in Fig.8(a) for $\mathrm{Gr}=0$, (no buoyancy) is characterized by perfect open lines along the horizontal axis joining the two openings on the first story, while the enclosed convective cells are observed in the second and the third stories of the divided high building. Increasing Gr to $10^{4}$, Fig.8(b ) shows a big change in the flow structure; a multicellular flow arises causing a big deformation of the open lines in the first story, just below the two natural convective cells generated in the second and the third story. The importance of the forced flow is visibly affected in Fig.8(c), corresponding to $\mathrm{Gr}=10^{5}$. A further increase of Gr leads to more important circulation cells above the open lines causing a visible tightening of these lines and showing a net domination of the natural convection effect, due to the heating of the higher portion of the left wall. Moreover, this increase of $\mathrm{Gr}$ contributes to the homogenization of temperature within the building by reducing the dimension of the cold zone, as shown by the isotherms. These aspects are shown in Fig.8 (d), plotted for $\mathrm{Gr}=10^{6}$, the Raleigh Bernard natural convective cells and the open lines, appear simultaneously in the stories. One can observe that this situation is a manifestation of the mixed convective heat and mass transfers in the building. Hence, the local Nusselt number along the left heated wall is an increasing function of the Grashof number as shown in fig.9 (a-c). This variation of the local Nusselt number proves that the local Nussselt number is inversely proportional to the heated flux which is correlated with Grashof number. By increasing Grashof number, the dimensionless temperature decreases, consequently the local Nusselt number increases. 


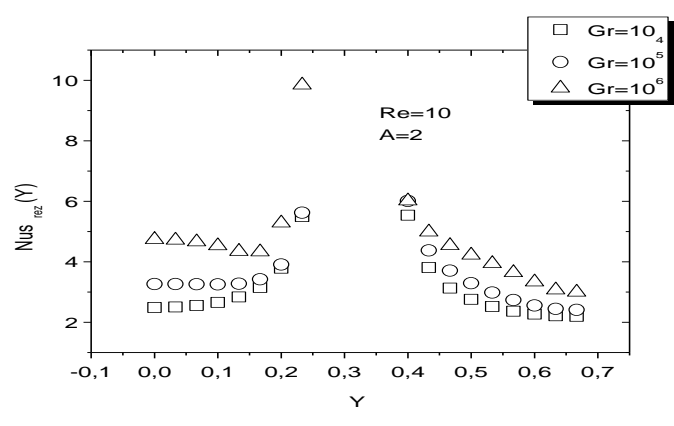

(a) First story left heated wall

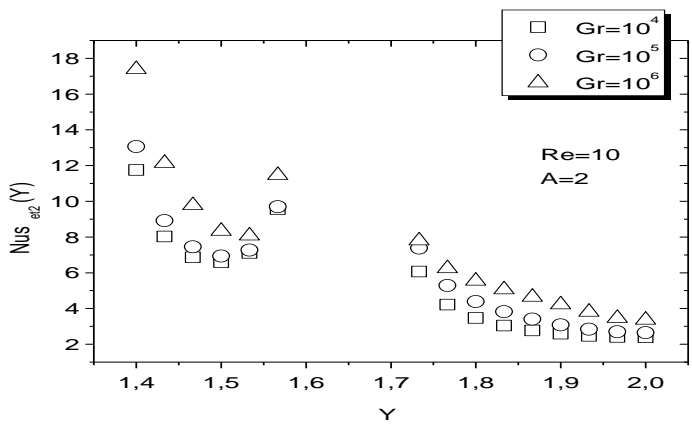

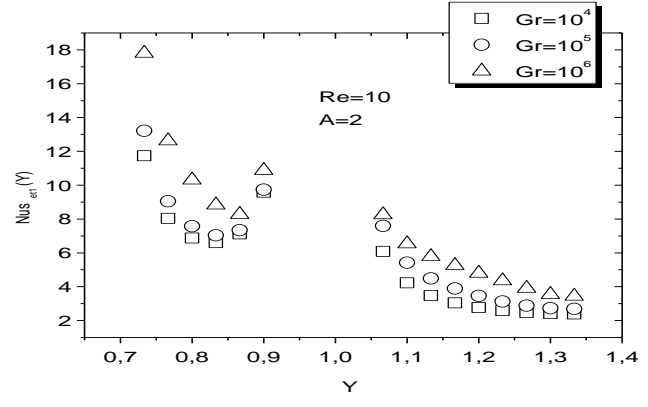

(b) Second story left heated wall

(c) Third story left heated wall

Fig.9:- Variation of Local Nusselt number along the left heated wall versus Grashof number

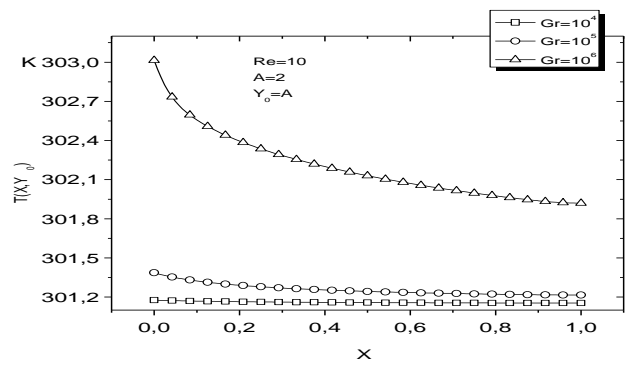

(a)Top node

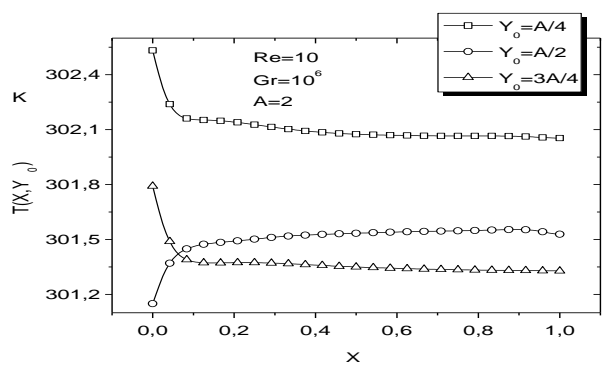

(b)Internal node

Fig.10:- Variation of temperature versus Grashof number

In fig.10 (a) the coolant fluid temperature is an increasing function of the Grashof number. One can observe that the temperature decreases along the horizontal axis which relates the left heated wall to the right adiabatic wall. This situation indicates that the temperature is stratified from the left heated wall to the right adiabatic wall. Fig.10 (b) showed that temperature is stratified along the vertical axis on the stories. Air movement in the high divided building is significantly affected by the variation of the velocity components along the horizontal axis. Hence, fig.11 (a-d) showed that the vertical component of velocity increases to the maximal value before decreasing to the minimal value near the right adiabatic wall, while the horizontal component is decreasing and reaching the minimal value and then increasing to the maximal value near the right adiabatic wall. These variations of the velocity components indicate the presence of buoyancy forces in the building. Then for the fixed Reynolds number, the vertical velocity component is an increasing function of Grashof number near the left heated wall while it is a decreasing function near the right adiabatic wall fig.11 $(a, b)$, due to the opposed variation for the horizontal velocity component as shown in fig. 11(c, d). 


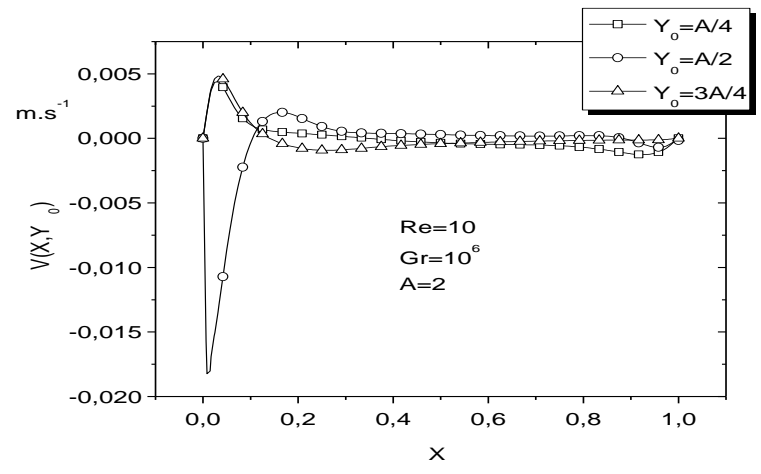

(a)

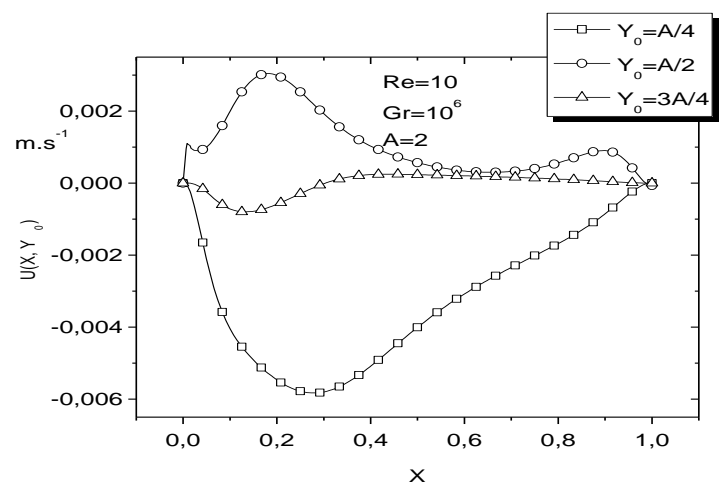

(c)

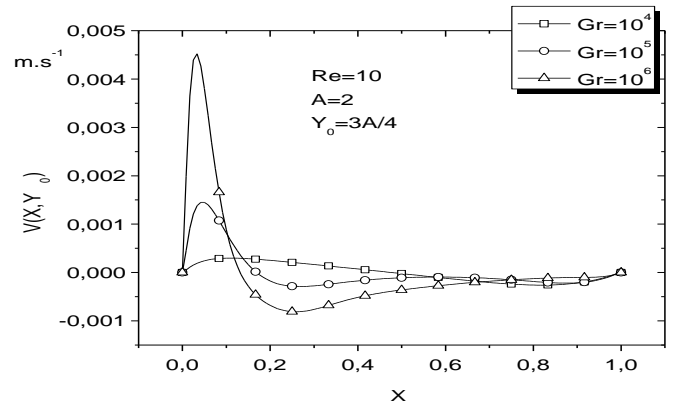

(b

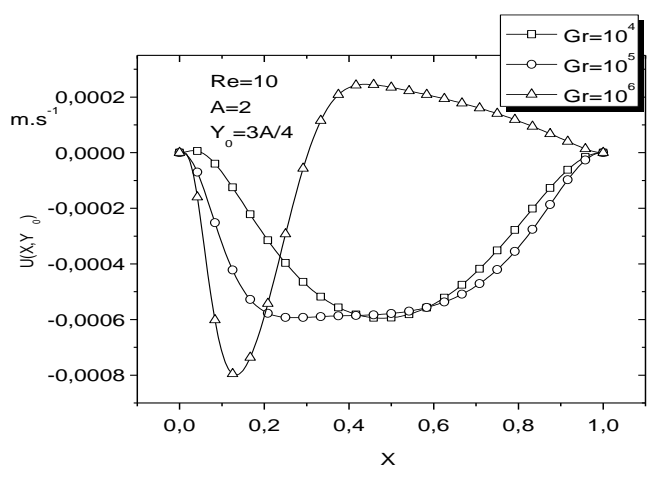

(d)

Fig.11:-Variation of the vertical and horizontal components of velocity versus Reynolds number

\section{Effect Of Geometrical Aspect Ratio (A):-}

The geometrical aspect ratio is one of the most important control parameters for passive cooling in buildings. The plotted streamlines and isotherms obtained are shown in fig.12 (a-c) for different values of the geometrical aspect ratio. For fixed Reynolds and Grashof numbers $\left(\mathrm{Re}=10 ; \mathrm{Gr}=10^{5}\right)$, the fig.12(a) indicated for $\mathrm{A}=1$, the manifestation of the mixed convection in the entire divided building. There is a coexistence of the open lines and the natural convective enclosed cells on the floors. The corresponding isothermal lines are tightened in the vicinity of the left heated wall along the building. By increasing the geometrical aspect ratio fig.12 (b, c), heat transfer exchange increases. The enclosed natural convective cells disappear progressively in favor of the open lines. Then several open lines appear on the first story for the case of $A=2.5$. One can conclude that the cold zone in the building increases by increasing the geometrical aspect ratio (A), and the flow structure becomes more and more complex. The natural convective recirculation cells are deformed. Consequently, the vertical and the horizontal components of the coolant fluid velocity are decreasing functions of the geometrical aspect ratio, fig.13 (a-b). 
a

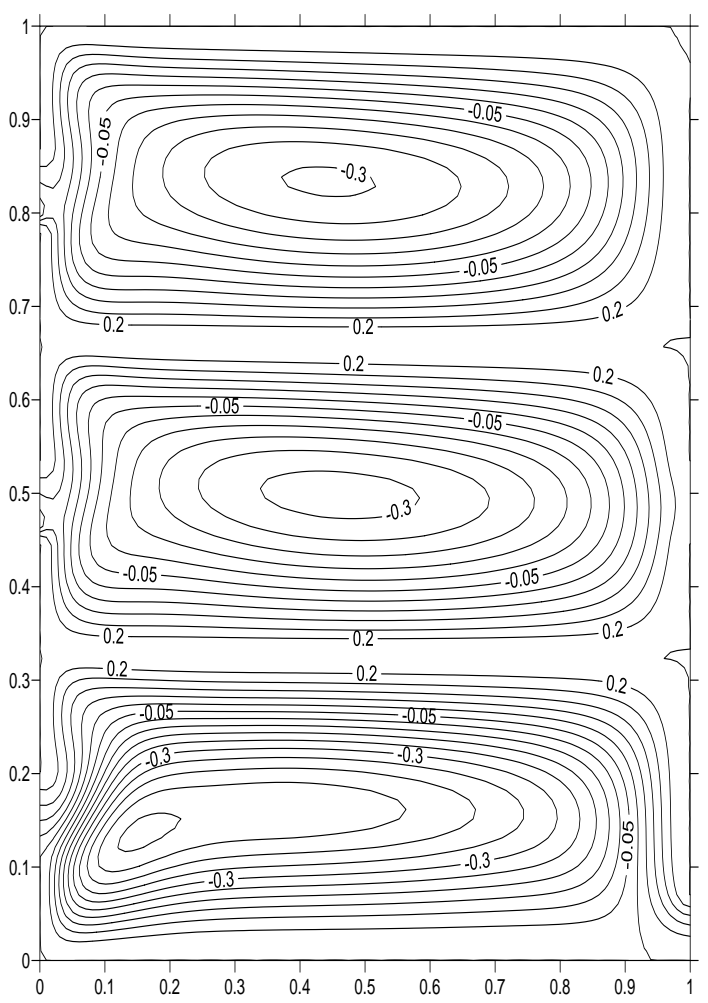

b

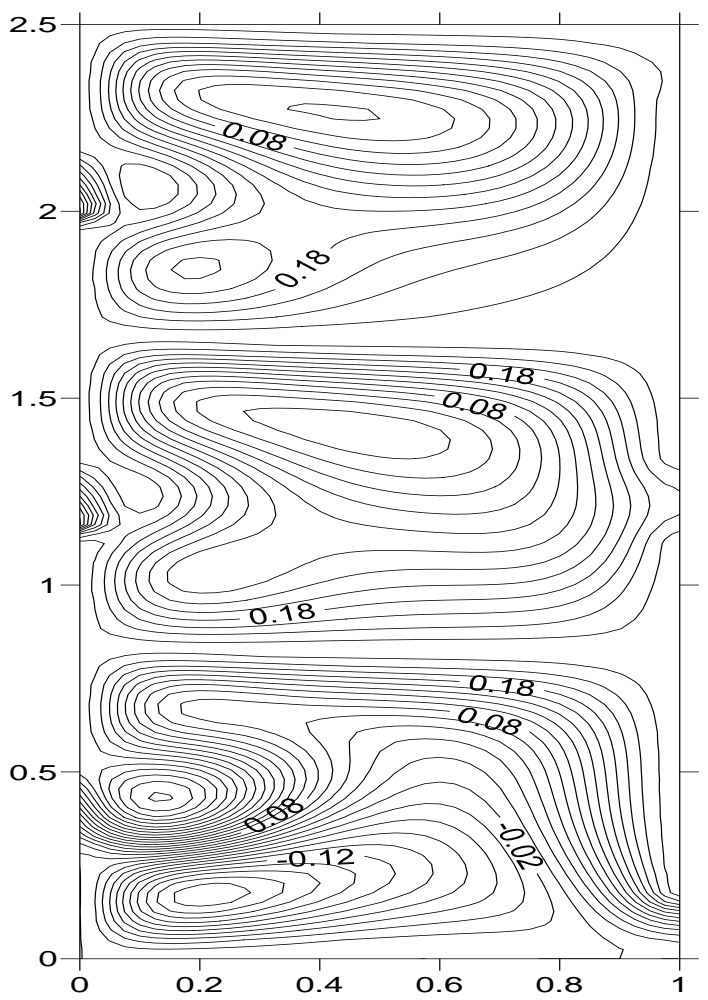

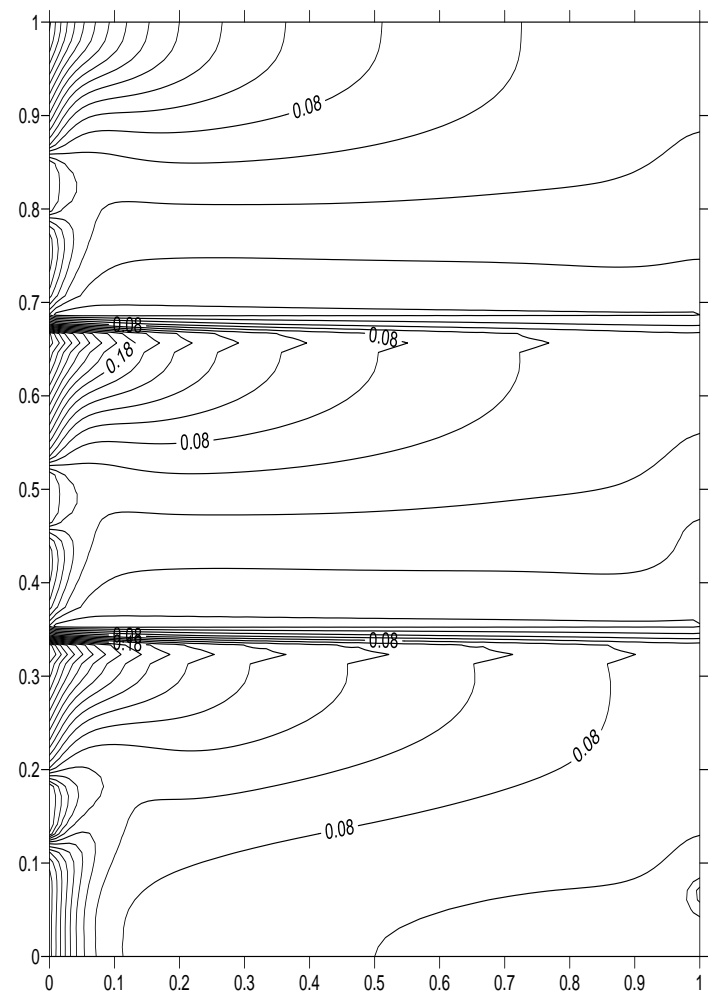

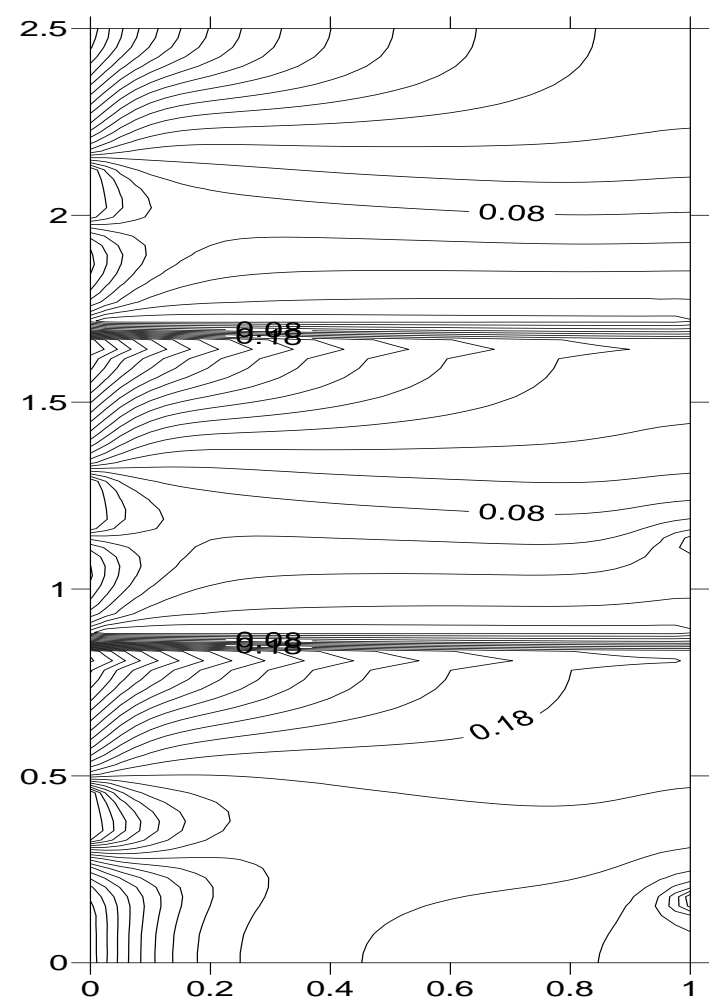



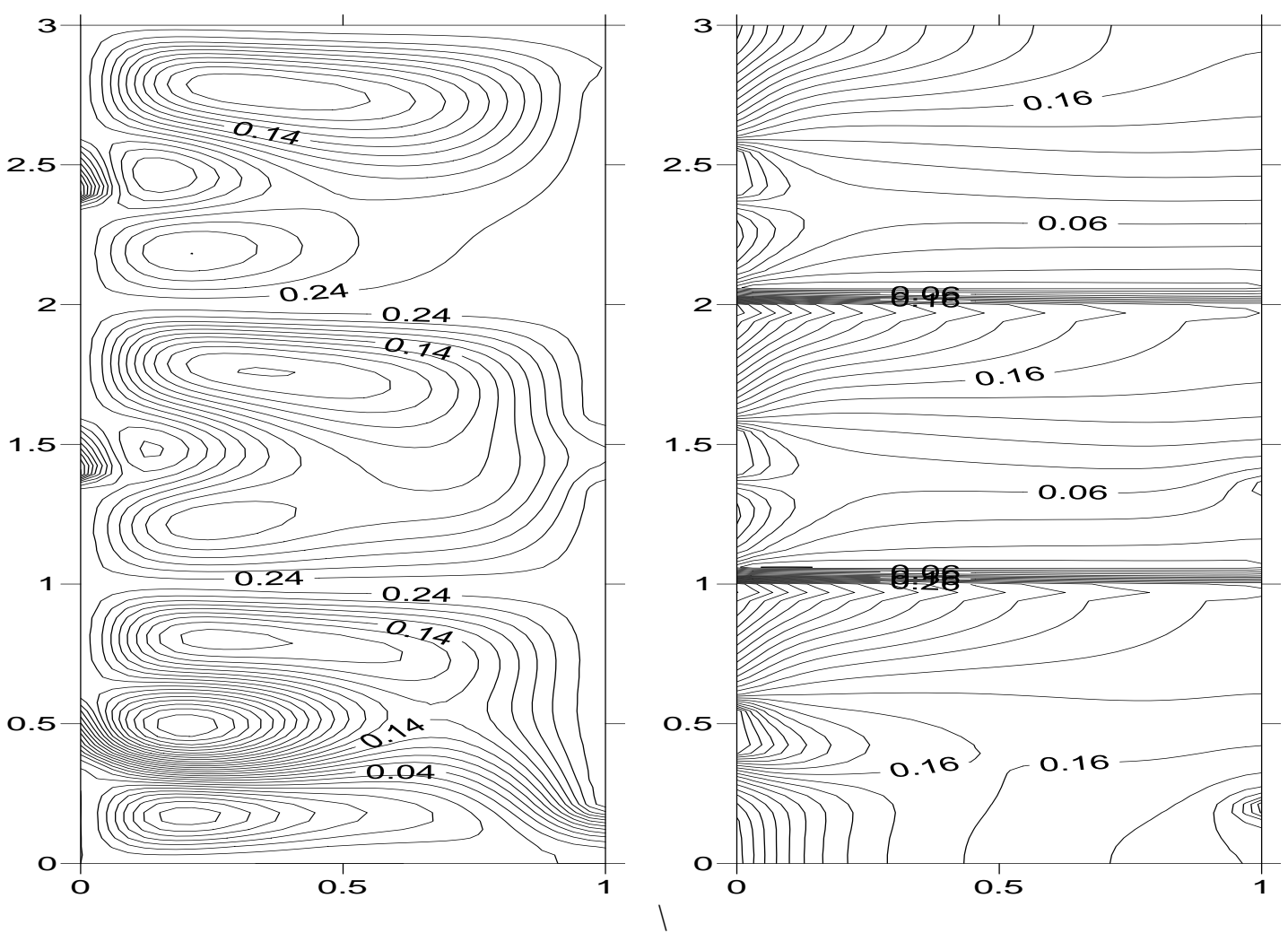

Fig .12:-Streamlines and isotherms obtained for $\mathrm{Re}=10 ; \mathrm{Gr}=10^{5}$ for different geometrical aspect ratio values: (a) $\mathrm{A}=1$; (b) $\mathrm{A}=2.5$; (c) $\mathrm{A}=3$

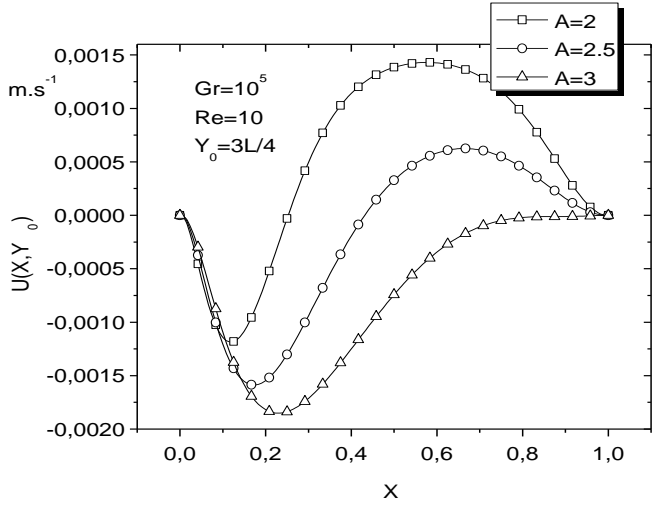

(a) Horizontal component

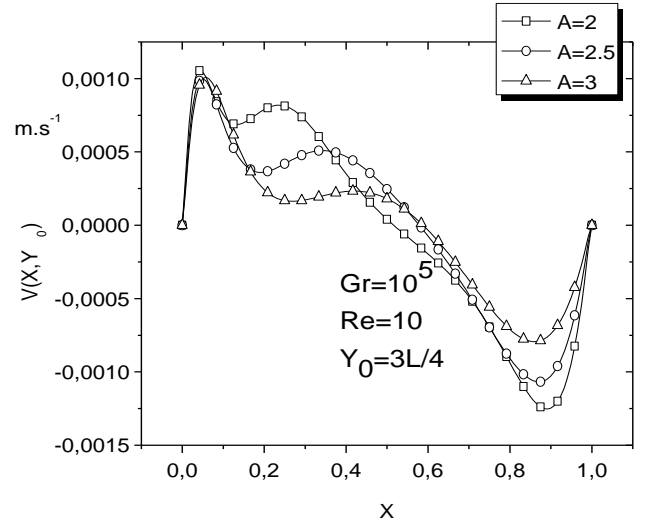

(b) Vertical component

Fig.13:-Variation of the horizontal and the vertical components of the air velocity versus the geometrical aspect ratio. 


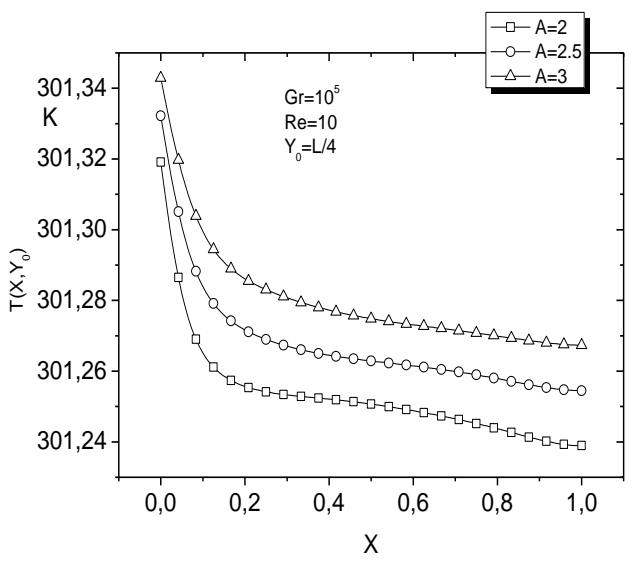

(a)

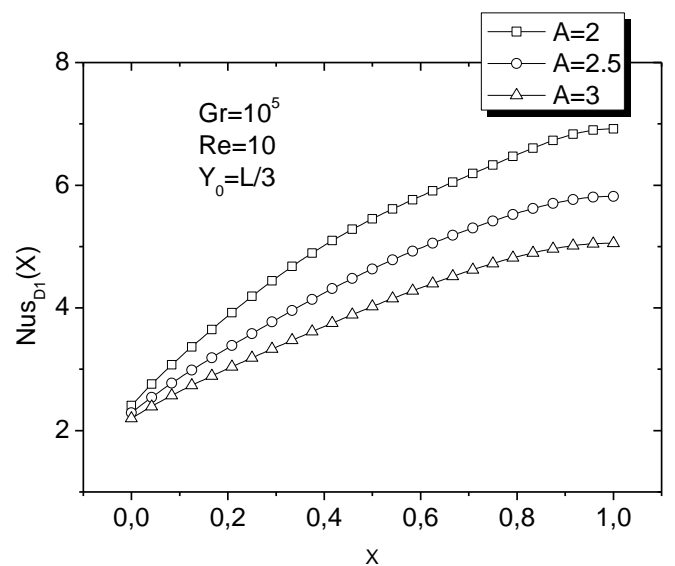

(b)

Fig.14:-Variation of the temperature and the local Nusselt number along the length of the building versus the geometrical aspect ratio.

Fig.14 (a) showed that temperature is an increasing function of the geometrical aspect ratio while the local Nusselt number is a decreasing function of the geometrical aspect ratio, fig.14 (b). These variations of the temperature and Nusselt number confirmed the existence of a relation between the heated flux, the height of the building and dimensionless temperature.

\section{Conclusion:-}

The numerical investigation in this study allowed the authors to know that air flow in a high divided building for the lowest value of Reynolds number is natural convection while it is forced convection for the highest value of Reynolds number. The role of air flow is to extract the excess heat along the left heated wall. Flow analysis in the high divided building has given several possibilities to reduce the energy charge for air conditioning and provide passive cooling on the stories. Within the investigated parameters ranges, the following conclusions can be drawn:

- Coolant fluid temperature is an increasing function of the geometrical aspect ratio while the local Nusselt number is a decreasing function.

- Openings give the possibility to decrease conventional electrical energy consumption charge for air conditioning in a divided multi-storied high building.

- Openings provide passive venting and thermal comfort by natural convection on the floors in the high building.

- For the lowest values of Grashof and Reynolds numbers, thermal comfort is attained in a high building divided into three stories.

Nomenclature:-

\begin{tabular}{|l|l|}
\hline $\mathrm{C}_{\mathrm{P}}$ & Specific heat $\left(\mathrm{J}_{\mathrm{kg}} \mathrm{kg}^{-1} \cdot \mathrm{K}^{-1}\right)$ \\
\hline $\mathrm{H}$ & Building Length $(\mathrm{m})$ \\
\hline $\mathrm{L}$ & Building height $(\mathrm{m})$ \\
\hline $\mathrm{L}_{\mathrm{rez}}$ & First story height $(\mathrm{m})$ \\
\hline $\mathrm{L}_{\mathrm{B}}$ & Height of the building before the first inlet opening \\
\hline $\mathrm{e}$ & Inlet /outlet opening $(\mathrm{m})$ \\
\hline $\mathrm{A}$ & Geometrical aspect ratio of the building $(\mathrm{A}=\mathrm{L} / \mathrm{H})$ \\
\hline $\mathrm{S}$ & Aspect ratio of the building $\left(S=H / L_{r e z}\right)$ \\
\hline $\mathrm{E}$ & Inlet/outlet opening aspect ratio $\left(E=e / L_{r e z}\right)$ \\
\hline $\mathrm{g}$ & Gravitational acceleration $\left(\mathrm{m} \cdot \mathrm{s}^{-2}\right)$ \\
\hline $\mathrm{n}$ & Coordinate in normal direction \\
\hline $\mathrm{t}$ & Time $(\mathrm{s})$ \\
\hline $\mathrm{T}$ & Temperature $(\mathrm{K})$ \\
\hline $\mathrm{T}_{\mathrm{a}}$ & Ambient air temperature $(\mathrm{K})$ \\
\hline $\mathrm{u}, \mathrm{v}$ & Velocity component in $\mathrm{x}$ and y directions $\left(\mathrm{m} \cdot \mathrm{s}^{-1}\right)$ \\
\hline
\end{tabular}




\begin{tabular}{|c|c|}
\hline U, V & Dimensionless velocity component in $\mathrm{X}$ and $\mathrm{Y}$ directions; $\mathrm{U}=\mathrm{u} / \mathrm{u}_{0}, \mathrm{~V}=\mathrm{v} / \mathrm{u}_{0}$ \\
\hline $\mathrm{u}_{0}$ & Air inlet velocity $\left(\mathrm{m} \cdot \mathrm{s}^{-1}\right)$ \\
\hline $\mathrm{x}, \mathrm{y}$ & Coordinates defined in fig. $1(\mathrm{~m})$ \\
\hline $\mathrm{X}, \mathrm{Y}$ & Dimensionless spatial coordinates; $\mathrm{X}=\mathrm{x} / \mathrm{L}_{\mathrm{rez}}, \mathrm{Y}=\mathrm{y} / \mathrm{L}_{\mathrm{rez}}$ \\
\hline $\operatorname{Re}$ & Reynolds number: $\operatorname{Re}=\frac{\rho u_{0}(2 e)}{\mu}$ \\
\hline $\operatorname{Pr}$ & Prandlt number : $\operatorname{Pr}=\mu C p / \lambda$ \\
\hline $\mathrm{Nu}$ & Nusselt number : $N u=\frac{\varnothing L_{r e z}}{\lambda\left(T-T_{a}\right)}=\frac{1}{\theta}$ \\
\hline $\mathrm{Gr}$ & Grashof number $\backslash$ dimensionless $G r=\frac{g \beta \emptyset L_{r e z}^{4}}{\lambda V^{2}}$ \\
\hline $\mathrm{Ri}$ & Thermal Richardson number ( $\left.R i=G r / \mathrm{Re}^{2}\right)$ \\
\hline \multicolumn{2}{|c|}{ Greek symbols } \\
\hline$\theta$ & Dimensionless temperature $\theta=\frac{\lambda\left(T-T_{a}\right)}{\emptyset L_{r e z}}$ \\
\hline$\tau$ & Dimensionless time $\quad \tau=\frac{u_{0} t}{L_{r e z}}$ \\
\hline$\Psi$ & Dimensionless stream function: $\Psi=\frac{\psi}{L_{r e z} u_{0}}$ \\
\hline$\omega$ & Dimensionless vorticity: $\omega=\frac{\Omega L_{r e z}}{u_{0}}$ \\
\hline$\Omega$ & Vorticity $\left(\mathrm{s}^{-1}\right)$ \\
\hline$\psi$ & Stream function $\left(\mathrm{m} . \mathrm{s}^{-2}\right)$ \\
\hline$\beta$ & Thermal expansion coefficient $\left(\mathrm{K}^{-1}\right)$ \\
\hline$\rho$ & Density of the air $\left(\mathrm{kg} \cdot \mathrm{m}^{-3}\right)$ \\
\hline$\lambda$ & Thermal diffusivity of the air $\left(\mathrm{W} \cdot \mathrm{m}^{-1} \cdot \mathrm{K}^{-1}\right)$ \\
\hline$\mu$ & Dynamic viscosity of the air $\left(\mathrm{kg} \cdot \mathrm{m}^{-1} \cdot \mathrm{s}^{-1}\right)$ \\
\hline$\phi$ & Solar radiation $\left(\mathrm{W} . \mathrm{m}^{-2}\right)$ \\
\hline$v$ & Cinematic viscosity $\left(\mathrm{m}^{2} \cdot \mathrm{s}^{-1}\right)$ \\
\hline \multicolumn{2}{|c|}{ subscripts } \\
\hline f & Fluid (air) \\
\hline W & Wall \\
\hline moy & Mean \\
\hline $\max$ & Maximum \\
\hline
\end{tabular}




\section{References:-}

1. A. Raji, M. Hasnaoui. Mixed convection heat transfer in ventilated cavities with opposing and assisting flows. http://www.emerald-library.com.PP 556 - 572.

2. Dubovsky V, Ziskind G, Druckman S, Moshka E, Weiss Y, Letan R. Natural convection inside ventilated enclosure heated by downward-facing plate: experiments and numerical simulations. International Journal of Heat and Mass Transfer 2001;44(16): 3155-68.

3. Druckman S, Moshka E, Dubovsky V, Letan R, Weiss Y,Ziskind G. Visualization of natural convection inside a ventilated enclosure. Proceedings of the Ninth International Symposium on Flow Visualization, Edinburgh, 2000.

4. Deng, Q.H., Zhou, J., Mei, C., Shen, Y.M., 2004. Fluid, heat and contaminant transport structures of laminar double-diffusive mixed convection in a two-dimensional ventilated enclosure. Int. J. Heat Mass Transfer 47, 5257-5269. Laboratory, Department of Mechanical Engineering, Ben-Gurion University of the Negev, 2000.

5. Glat Y, Aviv A. Ventilation of an enclosure by natural convection with a hot vertical plate in the chimney. Graduation Project 00-04 (supervised by R. Letan and Y. Weiss), Heat Transfer Laboratory, Department of Mechanical Engineering, Ben-Gurion University of the Negev, 2000.

6. Hsu, T.H., Hsu, P.T., How, S.P., 1997. Mixed convection in a partially divided rectangular enclosure. Numer. Heat Transfer Part A 31, 655-683.

7. I.Catton. Natural convection in enclosures, in: Proceedings of $6^{\text {th }}$ Int. Heat Transfer Conference, Toronto Vol. 6 (1979), pp. 13-43.

8. J.L. Lage, A. Bejan, R. Anderson, Efficiency of transient contaminant removal from a slot ventilated enclosure, Int. J. Heat Mass Transfer 34 (10). 1991. 2603-2615.

9. J.L. Lage, A. Bejan, R. Anderson, Removal of contaminant generated by a discrete source in a slot ventilated enclosure, Int. J. Heat Mass Transfer 35 (5)._1992. 1169-1180.

10. Manca, O., Nardini, S., Khanafer, K., Vafai, K., 2003. Effect of heated wall position on mixed convection in a channel with an open cavity. Numer. Heat Transfer Part A 43, 259-282.

11. Mazal B, Medina O. Ventilation control in a multi-storey structure. Graduation Project 01-80 (supervised by R. Letan and G. Ziskind),Heat Transfer Laboratory, Department of Mechanical Engineering,Ben-Gurion University of the Negev, 2001.

12. Oosthuizen, P.H., Paul, J.T., 1985. Mixed convective heat transfer in a cavity. ASME HTD 42, $159-169$.

13. Papanicolaou, E., Jaluria, Y., 1990. Mixed convection from an isolated heat source in a rectangular enclosure. Numer. Heat Transfer Part A18, 427-461.

14. Papanicolaou, E., Jaluria, Y., 1993. Mixed convection from a localized heat source in a cavity with conducting walls: a numerical study. Numer. Heat Transfer Part A 23, 463-484.

15. Papanicolaou, E., Jaluria, Y., 1994. Mixed convection from simulated electronic components at varying relative positions in a cavity. ASME J. Heat Transfer 116, 960-970.

16. R. Letan, V. Dubovsky, G. Ziskind. Passive ventilation and heating by natural convection in a multi-storey building. Building and Environment 38 (2003) 197 - 208

17. Raji, A., Hasnaoui, M., 1998a. Mixed convection heat transfer in a rectangular cavity ventilated and heated from the side. Numer. Heat Transfer Part A 33, 533-548.

18. Raji, A., Hasnaoui, M., 2000. Mixed convection heat transfer in ventilated cavities with opposing and assisting flows. Eng. Comput. Int. J. Comput.-Aided Eng. Softw. 17, 556-572.

19. Singh, S., Sharif, M.A.R., 2003. Mixed convective cooling of a rectangular cavity with inlet and exit openings on differentially heated side walls. Numer. Heat Transfer Part A 44, 233-253.

20. S. Ostrach, Natural convection in enclosure, in: J.P. Hartnell, T.F. Irvine _Eds.., Advances in Heat Transfer Vol. 8 Academic Press,New York, 1972.

21. Woods L.C., A note of numerical solution of fourth differential equations, Aero. Q. 5 (1954) 176-1 84.

22. Ziskind G, Dubovsky V, Letan R. Ventilation by natural convection of a one-storey building. Energy and Buildings 2002;34(1):93-104.

23. Ziskind G, Dubovsky V, Letan R. Removal of contaminants by induced 9ow inside structures, paper HTD24329, vol. 5. Proceedings of ASME International Mechanical Engineering Congress and Exposition, New York, November 2001. ASME Heat Transfer

24. Division, Book No. I00530. 